\title{
Mediator Med23 Regulates Adult Hippocampal Neurogenesis
}

\author{
Guo-Yan Chen 1,2, Shuai Zhang ${ }^{3,4}$, Chong-Hui Li3, Cong-Cong Qi ${ }^{5}$, Ya-Zhou Wang ${ }^{6}$, \\ Jia-Yin Chen ${ }^{2}$, Gang Wang ${ }^{3,7 *}$, Yu-Qiang Ding ${ }^{2,5 *}$ and Chang-Jun Su ${ }^{1 *}$
}

\section{OPEN ACCESS}

Edited by:

Carmen Castro,

University of Cádiz, Spain

Reviewed by:

Aixa Victoria Morales,

Cajal Institute (CSIC), Spain

Giuseppe Lupo,

Sapienza University of Rome, Italy

${ }^{*}$ Correspondence:

Gang Wang

gwang_fd@fudan.edu.cn

Yu-Qiang Ding

dingyuqiang@vip.163.com

Chang-Jun Su

changjunsu@163.com

Specialty section:

This article was submitted to

Stem Cell Research,

a section of the journal

Frontiers in Cell and Developmental

Biology

Received: 27 March 2020

Accepted: 09 July 2020

Published: 29 July 2020

Citation:

Chen G-Y, Zhang S, Li C-H,

Qi C-C, Wang Y-Z, Chen J-Y,

Wang G, Ding Y-Q and Su C-J (2020)

Mediator Med23 Regulates Adult

Hippocampal Neurogenesis.

Front. Cell Dev. Biol. 8:699.

doi: 10.3389/fcell.2020.00699
Mammalian Mediator (Med) is a key regulator of gene expression by linking transcription factors to RNA polymerase II (Pol II) transcription machineries. The Mediator subunit 23 (Med23) is a member of the conserved Med protein complex and plays essential roles in diverse biological processes including adipogenesis, carcinogenesis, osteoblast differentiation, and T-cell activation. However, its potential functions in the nervous system remain unknown. We report here that Med23 is required for adult hippocampal neurogenesis in mouse. Deletion of Med23 in adult hippocampal neural stem cells

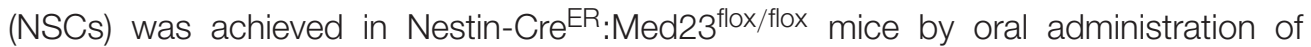
tamoxifen. We found an increased number of proliferating NSCs shown by pulse BrdUlabeling and immunostaining of MCM2 and Ki67, which is possibly due to a reduction in cell cycle length, with unchanged $\mathrm{GFAP}^{+} / \mathrm{Sox}^{+} \mathrm{NSCs}$ and $\mathrm{Tbr}^{+}$progenitors. On the other hand, neuroblasts and immature neurons indicated by NeuroD and DCX were decreased in number in the dentate gyrus (DG) of Med23-deficient mice. In addition, these mice also displayed defective dendritic morphogenesis, as well as a deficiency in spatial and contextual fear memory. Gene ontology (GO) analysis of hippocampal NSCs revealed an enrichment in genes involved in cell proliferation, Pol II-associated transcription, Notch signaling pathway and apoptosis. These results demonstrate that Med23 plays roles in regulating adult brain neurogenesis and functions.

Keywords: Mediator complex 23, hippocampus, proliferation, cell cycle, adult neural stem cells

\section{INTRODUCTION}

The mammalian Mediator complex is an evolutionarily conserved multi-protein complex, which functions as a key transcriptional cofactor by forming a link between sequence-specific transcription factors and the RNA polymerase II (Pol II)-associated basal transcription machinery. In this context, it may be required for the transcription of thousands of protein-coding genes (Lewis and Reinberg, 2003; Malik and Roeder, 2005; Hentges, 2011). The Mediator complex contains up to 
30 proteins, and given its fundamental role in gene transcription, inactivation of individual genes may lead to global gene expression defects. However, based on data showing that mutation of different Mediator complex genes in the same organism leads to different phenotypes, individual Mediator complex proteins have unique biological functions (Bourbon et al., 2004; Malik and Roeder, 2010; Hentges, 2011).

The Mediator subunit 23 (Med23, also known as sur2) was originally identified as a genetic suppressor of activated let60 ras mutation in Caenorhabditis elegans (Singh and Han, 1995). Med23 functions in the mitogen-activated protein kinase (MAPK) signaling pathway by interacting with the ternary complex factor Elk1, and data from embryonic fibroblasts have indicated that MAPK-activated interaction of Med23-Elk1 is required for hormone-induced adipogenesis through controlling transcription of immediate early gene Egr2 (Stevens et al., 2002; Wang et al., 2005, 2009). Important roles of Med23 have also been reported in other biological processes including osteoblast differentiation (Liu et al., 2016), myogenesis (Yin et al., 2012), lung carcinogenesis (Yang et al., 2012; Yao et al., 2015), glucose and lipid metabolism (Chu et al., 2014), and T-cell activation (Sun et al., 2014).

Our previous study has shown that Med23-deficient embryonic stem cells display enhanced neural differentiation (Zhu et al., 2015). However, the roles of Med23 in the nervous system remain unknown. Importantly, a missense mutation of Med23 has been reported in patients with intellectual disability and dysregulation of expression of immediate early gene JUN and FOS (Hashimoto et al., 2011; Trehan et al., 2015). In this study, we focused on adult hippocampal neurogenesis in order to explore possible roles of Med23 within the brain.

Adult neurogenesis in the mammalian brain has received increased attention in recent years, especially because of its potential roles in neurological and psychiatric disorders. The process of adult neurogenesis includes the proliferation and differentiation of neural stem cells (NSCs), neuronal survival and migration, and integration of newborn neurons into existing circuits (Zhao et al., 2008; Ming and Song, 2011). The subgranular zone (SGZ) in the dentate gyrus (DG) of the hippocampus is one of the active neurogenic niches of the adult brain (Morales and Mira, 2019). Impaired SGZ neurogenesis is associated with defective spatial learning and memory, and retrieval of contextual fear memory in mice (Zhang et al., 2013, 2014; Lieberwirth et al., 2016). It has also been reported that enhanced hippocampal neurogenesis is involved in mediating the antidepressant effects of fluoxetine and cognition in Alzheimer's mouse model (Santarelli et al., 2003; Choi et al., 2018).

Here, we provide evidence that Med23 is involved in the regulation of adult hippocampal neurogenesis in mouse. Med23-deficient NSCs in the SGZ display faster self-renewal activity possibly by reducing cell cycle length, but neuroblasts, immature and mature new-born neurons are reduced. In addition, inducible Med23 conditional knockout (CKO) mice show defects in spatial and contextual fear memory. Gene ontology (GO) analysis of Med23deficient NSCs reveals an enrichment in genes involved in cell proliferation, Pol II-associated transcription, Notch signaling pathway and apoptosis. Taken together, these results demonstrate that Med23 is an important regulator of adult brain functions.

\section{MATERIALS AND METHODS}

\section{Animals}

To investigate the role of Med23 in adult hippocampal neurogenesis, we first generated Nestin-Cre ${ }^{\mathrm{ER}}: \mathrm{Med} 23^{\text {flox/+ }}$ mice by crossing Nestin-Cre ${ }^{\mathrm{ER}}$ (Imayoshi et al., 2008) with Med23 flox/flox mice with two LoxP sites flanking exons 57 of Med23 allele as described in our previous study (Chu et al., 2014). Nestin-Cre ${ }^{\mathrm{ER}}:$ Med2 $3^{\text {flox/+ }}$ mice were further crossed with Med2 $3^{\text {flox } / \text { flox }}$ mice to obtain Nestin-Cre ${ }^{\text {ER }}$ :Med2 $3^{\text {flox } / \text { flox }}$ (Med23 CKO) mice. Littermates with other genotypes (i.e., Med2 $3^{\text {flox } /+}$ and Med2 $3^{\text {flox/flox }}$ ) were used as controls, because they did not exhibit any detectable alterations in the SGZ (see below). To visualize Med23-deficient NSCs and its progeny in vivo using Rosa26-stop-YFP mice (Romer et al., 2011), Nestin$\mathrm{Cre}^{\mathrm{ER}}:$ Med23 $3^{\text {flox/flox}}:$ Rosa26-stop-YFP (referred to as Med23 CKO:Rosa-YFP) mice were generated by crossing Nestin$\mathrm{Cre}^{\mathrm{ER}}:$ Rosa26-stop-YFP:Med23 $3^{\text {flox/+ }}$ mice with $\mathrm{Med} 23^{\text {flox } /+}$ mice; in this set of experiments littermates with the genotype of Nestin-Cre ${ }^{\text {ER }}$ :Rosa26-YFP:Med23 $3^{+/+}$were used as controls, because they did not show any detectable alterations in the SGZ either. All animal experiments were carried out under the protocols approved by the Animal Care and Use Committees of Tongji University School of Medicine, China.

\section{Tamoxifen Administration}

To activate Cre-mediated recombination, Tamoxifen (TAM; $200 \mathrm{mg} / \mathrm{kg}$; Sigma) dissolved in corn oil solution (Sigma) was administered once daily by oral gavage for 5 consecutive days in adult ( 2 months) Med23 CKO mice. Littermate control mice received the same treatment. TM-treated mice were allowed to recover 3-4 weeks and then used in most experiments. In the experiment of hippocampal NSC culture, the TAM treatment were done at the age of one month.

\section{BrdU and EdU Administration}

To observe the survival of newborn neurons, mice were treated with TAM as described above, followed by intraperitoneal (i.p.) injection of 5-bromo-2' -deoxyuridine (BrdU; 100 mg/kg; Sigma) the day after, daily for 3 consecutive days, and sacrificed 21 days later. To observe proliferation of NSCs in the SGZ, mice were injected with BrdU (50 mg/kg) four times with a $2 \mathrm{~h}$ interval in-between injections were sacrificed $2 \mathrm{~h}$ after the last injection. To analyze cell cycle length of NSCs, mice received a single injection of BrdU (50 mg/kg), and were sacrificed 30 min later for double immunostaining of BrdU and $\mathrm{Ki} 67$ as described previously (Qu et al., 2013).

To explore the length of the S-phase of NSCs, mice were first injected with $57.5 \mathrm{mg} / \mathrm{kg}$ of 5-ethynyl-2' -deoxyuridine (EdU; Life Technologies), followed by another single injection of $42.5 \mathrm{mg} / \mathrm{kg}$ BrdU $3 \mathrm{~h}$ later. Mice were sacrificed $45 \mathrm{~min}$ later 
for double staining of BrdU and EdU as described previously (Brandt et al., 2012).

\section{Immunostaining of BrdU, EdU, and Ki67}

For BrdU detection, sections were incubated in $2 \mathrm{~N} \mathrm{HCl}$ for $25 \mathrm{~min}$ at $37^{\circ} \mathrm{C}$ prior to neutralization with $0.01 \mathrm{M}$ sodium borate ( $\mathrm{pH} 8.5$ ) for $10 \mathrm{~min}$. Sections were washed in phosphatebuffered saline (PBS) and incubated with mouse anti-BrdU (1:400; Calbiochem) at $4^{\circ} \mathrm{C}$ overnight. Then sections were incubated with biotinylated horse anti-mouse (1:500; Vector) for $3 \mathrm{~h}$ and finally with Cy3-conjugated streptavidin (1:1000; Sigma) for $1 \mathrm{~h}$ at room temperature (RT).

For double staining of BrdU and EdU, sections were processed for detection of BrdU first as described above, followed by EdU staining as follows: incubation of sections for $3 \mathrm{~h}$ at RT in PBS containing $1 \mathrm{mM} \mathrm{CuSO} 4,50 \mathrm{mM}$ ascorbic acid and $10 \mu \mathrm{M}$ fluorescent azide 488 (Salic and Mitchison, 2008).

For double staining of $\mathrm{BrdU}$ and $\mathrm{Ki} 67, \mathrm{HCl} /$ sodium boratepretreated sections were incubated with a mixture of rat antiBrdU (1:1000; Accurate) and rabbit anti-Ki67 (1:400; Leica), then with biotinylated horse anti-rat IgG (1:500; Vector) for $3 \mathrm{~h}$, and finally with a mixture of Cy3-conjugated streptavidin (1:1000; Sigma) and 488-donkey anti-rabbit (1:500; Invitrogen) for $1 \mathrm{~h}$ at RT.

\section{Immunostaining, in situ Hybridization and TUNEL Staining}

Under deep anesthesia with sodium pentobarbital (Merck), mice were transcardially perfused with $0.1 \mathrm{M}$ PBS ( $\mathrm{pH}$ 7.4) followed by $4 \%$ paraformaldehyde (PFA) in PBS. After cryoprotection with $30 \%$ sucrose in PBS, brains were cut into $30-\mu$ m-thick coronal sections on a cryostat, which were then treated with $0.01 \mathrm{M}$ citrate buffer $(\mathrm{pH} 6.0)$ at $95^{\circ} \mathrm{C}$ for $7 \mathrm{~min}$ before incubating with the following primary antibodies for single or double immunostaining: rabbit anti-Ki67 (1:400; Leica), mouse anti-MCM2 (1:800; BD Pharmingen), goat anti-Sox2 (1:200; Santa Cruz), rabbit anti-glial fibrillary acidic protein (GFAP; 1:1000; DAKO), goat anti-doublecortin (DCX; 1:400; Santa Cruz), goat anti-NeuroD (1:400; Santa Cruz), rabbit antiGFP (1:1000; Life Tech), mouse anti-NeuN (1:1000; Millipore) or rabbit anti-cleaved caspse3 (1:1000; Abcam). Sections were washed in PBS and incubated with appropriate secondary antibodies: biotinylated horse anti-goat IgG (1:500; Vector), 488donkey anti-rabbit (1:500; Invitrogen), biotinylated goat antirabbit (1:500; Vector), biotinylated horse anti-mouse (1:500; Vector) or 488-donkey anti-rabbit (1:500; Invitrogen) at RT for $3 \mathrm{~h}$. For biotinylated secondary antibodies, sections were washed in PBS and incubated with Cy3-conjugated streptavidin (1:1000; Sigma) for $1 \mathrm{~h}$ at RT. In addition, in situ hybridization of Tbr2 was performed in brain slice as described previously (Pruski et al., 2019), the sequence of primers for making RNA probe of Tbr2 were: Forward, 5'-TTATCAGAGGAAGATGGCAGC3'; Reverse, 5'-AGAGCCCACTGTTAACTCAAGG-3'. TUNEL staining was performed in cultured NSCs and brain slice as described previously (Ding et al., 2003; Yang et al., 2018; Pruski et al., 2019).

\section{Western Blotting}

Hippocampal tissues were homogenized in RIPA lysis buffer as described previously (Yang et al., 2018). After SDS-PAGE and protein transfer, membranes were incubated with following primary antibodies: rabbit anti-DRIP130 (1:2000; Abcam) and mouse anti- $\beta$-actin (1:5000; Sigma) overnight at $4^{\circ} \mathrm{C}$, followed by incubation with HRP-conjugated anti-rabbit or anti-mouse IgG (1:2000; Proteintech) for $1 \mathrm{~h}$ at RT. Antibodies were visualized using an ECL kit (Thermo Fisher Scientific).

\section{Stereotactic Injections}

After anesthetizing with $10 \%$ chloral hydrate $(0.4 \mathrm{ml} / 100 \mathrm{~g}$ body weight), mice were stereotactically injected with $1 \mu \mathrm{l}$ of retrovirus expressing GFP (pRov-U6-shRNA-EF1a-EGFP) into the DG. Coordinates from the Bregma were (in $\mathrm{mm}$ ): -1.94 anterior/posterior $\pm 1.25 \mathrm{medial} / \mathrm{lateral}$, and $-2.0 \mathrm{dorsal} / \mathrm{ventral}$ from the dura mater. Twenty-one days later, animals were perfused as described above. Dendritic lengths and branch points of EGFP-labeled newborn neurons in the SGZ were traced with Image $J$ and analyzed.

\section{Hippocampal NSC Culture}

Primary NSC cultures were prepared from the hippocampus of 2-month-old Med23 CKO and littermate control mice as described previously with some modifications (Brewer and Torricelli, 2007). Briefly, under anesthesia with chloral hydrate, the hippocampus was removed and dissected in HABG, which contained B27 ( $1 \times$; Invitrogen), Glutamax ( $0.25 \times$; Invitrogen), and HA $(1 \times$; GIBCO $)$. Hippocampal tissues were digested in $0.025 \%$ Trypsin-EDTA $\left(1 \times\right.$; GIBCO) for $15 \mathrm{~min}$ at $37^{\circ} \mathrm{C}$, then DMEM $+10 \%$ FBS was added to terminate the reaction before centrifuging at $800 \mathrm{rpm}$ for $15 \mathrm{~min}$, and the tissue was finally dissociated into a single-cell suspension by mechanical disruption. The single-cell suspension was grown in Neurobasal-A Medium $(1 \times$; GIBCO), supplemented with B27-A ( $1 \times$; Invitrogen), L-glutamine (1×; Invitrogen), FGF (20 ng/ml; Invitrogen), EGF (20 ng/ml; Invitrogen), N2 (1×; Invitrogen $)$, and gentamicin $(0.01 \mathrm{mg} / \mathrm{ml}$; Invitrogen $)$. The desired cells were incubated at $37^{\circ} \mathrm{C}$ in $5 \% \mathrm{CO}_{2}$ for 8 days until primary neurospheres were formed. Primary neurospheres were mechanically dissociated into single cells and incubated for 5-6 days to allow secondary neurosphere formation. The sizes through measuring the length of primary and secondary neurospheres were recorded under a microscope (Nikon). Finally, primary neurospheres were harvested for quantitative real-time RT-PCR (qRT-PCR) (see below).

To evaluate the proportion of dividing cells in the neurospheres, primary neurospheres were treated with $10 \mu \mathrm{M}$ BrdU for $4 \mathrm{~h}$ and then subjected to immunostaining of BrdU as mentioned above.

\section{RNA Extraction and qRT-PCR}

Analyses were conducted with RNA extracts from primary neurospheres from Med23 CKO and control mice, harvested after 8 days of incubation. Total RNA was extracted as per Trizol (Life Technologies) protocol. cDNA was generated with iScript ${ }^{\mathrm{TM}}$ 
cDNA Synthesis Kit (Bio-Rad). qRT-PCR was performed using the ABI Prism 7500 Sequence Detector System. Primer sequences are as follows: $\beta$-actin (Forward: $5^{\prime}$-GGCTGTATTCCCCTC CATCG-3'; Reverse: 5'-CCAGTTGGTAACAATGCCATGT3'), Med23 (Forward: 5'-AGGAGTGGATTACAAGGGTG-3'; Reverse: 5'-TAGGCAGGCATTTCGTTC-3').

\section{RNA-Sequencing and Data Analysis}

An RNA-sequencing (RNA-seq) library was prepared from 8day cultured primary neurospheres using NEBNext ${ }^{\oplus}$ Ultra $^{\mathrm{TM}}$ RNA Library Prep Kit for Illumina (E7530) following the manufacturer's instructions, and all libraries were sequenced using the Illumina HiSeq platform. Raw.fastq files were analyzed using FastQC, and adapter removal was performed using cutadapt1.12. Reads were aligned to mouse genome assembly $\mathrm{mm}$ 10 using Tophat (Trapnell et al., 2009) with default parameters. Differential expression analysis was performed using Cuffdiff (Trapnell et al., 2012) and FPKM was calculated. GO analysis of differentially expressed genes was carried out using DAVID online tools ${ }^{1}$.

\section{Behavioral Tests}

Adult male mice (3-4 months old) were used in behavioral tests, and in the other experiments mice with either of sex were used. The experiments were performed during 9:00 a.m. to 5:00 p.m., and animal behaviors were videotaped. Mice were habituated in the test room for over $30 \mathrm{~min}$ before behavioral experiments. Ethanol (75\%) was used to clean arenas and objects between trials to remove excrements and odors for the following behavioral test (except forced swimming and tail suspension test). All behavioral tests were performed by a trained person who was blind to the genotypes.

\section{Morris Water Maze}

The Morris water maze was used to examine spatial memory (Vorhees and Williams, 2006). The apparatus contained two parts: a circle tank (120-cm diameter) and a hidden platform (10$\mathrm{cm}$ diameter) submerged $1-2 \mathrm{~cm}$ below the surface of the opaque water $\left(24-26^{\circ} \mathrm{C}\right)$. Mice movements were monitored and analyzed using EthoVision (8.0). In the spatial learning phase, mice were trained for four trials per day for 6 days at intertrial intervals of 40-50 min to discover the escape platform. The escape latencies of four trials per day were averaged for each animal. To test spatial memory, the hidden platform was removed and mice were subjected to retention tests 1 day after the spatial learning task. Memory retrieval was measured by quantifying the time spent in the target quadrant, the time taken to first cross the platform location, and the number of platform location crossings in a 1-min trial. Swim velocity was also measured during both the spatial learning and memory retrieval tasks.

\section{Contextual Fear Conditioning}

This test was used to assess contextual fear memory in mice, performed as described previously (Dai et al., 2008; Hu et al., 2014). In brief, mice freely explored the box for $10 \mathrm{~min}$ before the

\footnotetext{
${ }^{1}$ https://david.ncifcrf.gov
}

test, prior to being placed back in their home cage. About $1 \mathrm{~h}$ later, mice were placed in the box and given 5 foot shocks $(1.2 \mathrm{~mA}, 2 \mathrm{~s}$ duration) at 2-min intervals to learning contextual fear memory. To study retrieval of contextual fear memory, mice were placed in the conditioned fear context for $11 \mathrm{~min}$ to observe the percentage of freezing without any foot shock at $30 \mathrm{~min}$, on day 1 and day 7 .

\section{Novel Object Recognition Test}

This test was conducted in a black sound-proof chamber, containing a Plexiglas box $(25 \times 25 \times 25 \mathrm{~cm})$ and camera. The task procedure was described previously (Wang et al., 2007; Botton et al., 2010). In brief, the procedure consisted of three phases: habituation, familiarization, and test phase. In the habituation phase, the mouse was placed into the box without any object and allowed to explore for $10 \mathrm{~min}$ on day 1 . During familiarization, two identical sample objects $(\mathrm{A}+\mathrm{A})$ were placed into opposite corners of the box approximately $8 \mathrm{~cm}$ from the walls. A single mouse was placed into the box facing away from the objects and allowed to explore for $10 \mathrm{~min}$ on day 2. During the test phase, mouse was returned to the box which contained the location of novel (B) versus familiar object (A) about $1 \mathrm{~h}$ later, and allowed to explore for $5 \mathrm{~min}$. Exploration was defined by directing the nose to the object at a distance of no more than $2 \mathrm{~cm}$ and/or touching the object with the nose or forepaw. During the test phase, a recognition index for each mouse was expressed by $\mathrm{TN} /(\mathrm{TN}+\mathrm{TF})$ ratio $(\mathrm{TF}=$ time spent exploring familiar object; $\mathrm{TN}=$ time spent exploring novel object).

\section{Cell Count and Statistical Analysis}

Positive cells were counted in every 7th sections in the DG from anterior to posterior, expressed as count per $\mathrm{mm}^{3}$, by a trained observer who was blind to genotypes. All samples showed normal distribution examined by OriginPro9.1, and unpaired Student's $t$-test was performed using GraphPad Prism 5. Date are expressed as mean \pm SEM, and $p$-values $<0.05$ were considered to be statistically significant.

\section{RESULTS}

\section{Increased Number of Proliferating NSCs in Med23 CKO Mice}

To examine whether hippocampal NSCs are affected by the inactivation of Med23, we first performed BrdU pulse-labeling (Figure 1A) and quantified $\mathrm{BrdU}^{+}$cells in the $\mathrm{SGZ}$ as reported in our previous study (Song et al., 2016). Deletion of Med23 was confirmed by western blot of hippocampal tissues of Med23 CKO mice (Figure 1B), and by qRT-PCR analysis of Med23 transcript of neurospheres prepared from Med23 CKO mice (Figure 1C). Quantification of $\mathrm{BrdU}^{+}$cells in the DG showed a significant increase in Med23 CKO mice compared with controls (Figure 1D). In addition, cell cycle markers Ki67 (Figure 1E) and MCM2 (Figure 1F) were also significantly increased in the SGZ of Med23 CKO mice compared with controls. We next examined the population of $\mathrm{GFAP}^{+} / \mathrm{Sox} 2^{+}$ cells, which represent quiescent and active NSCs, and found no significant changes between control and Med23 CKO mice 
A
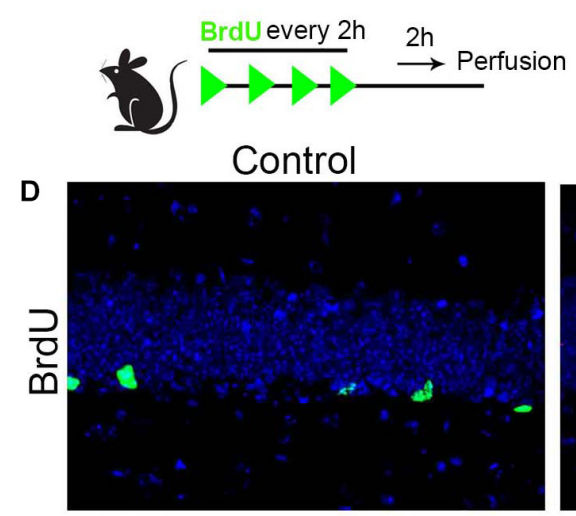

E

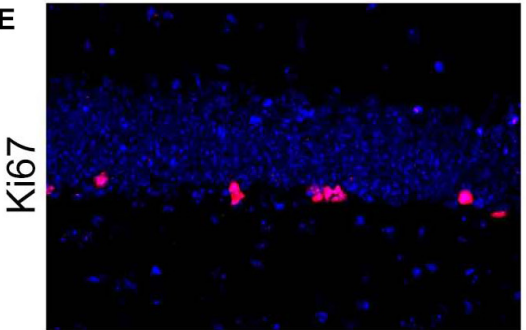

$\mathbf{F}$

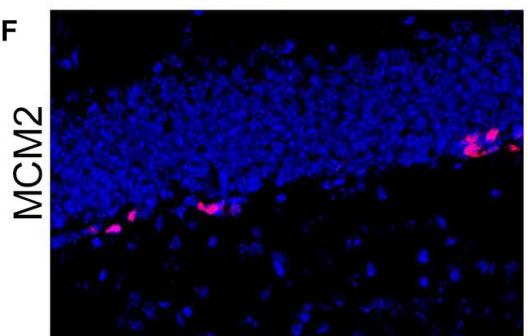

G
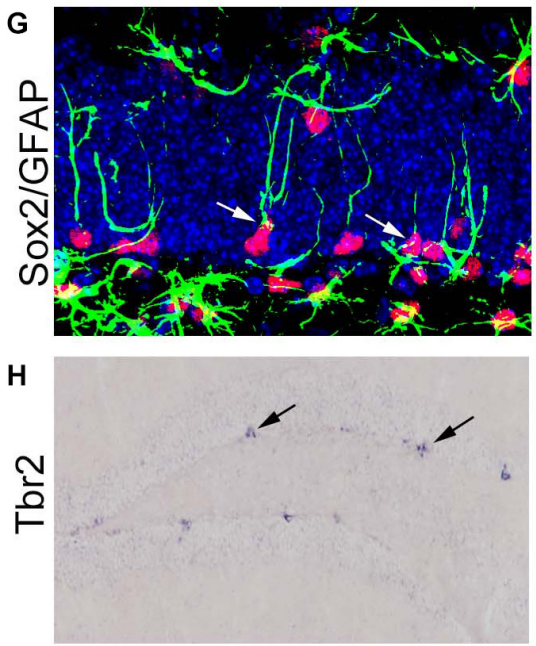

B Wild type Med23 CKO
Med23 $-+-\infty-\infty$
$\beta$-actin $-\ldots-\ldots$

Med23 CKO
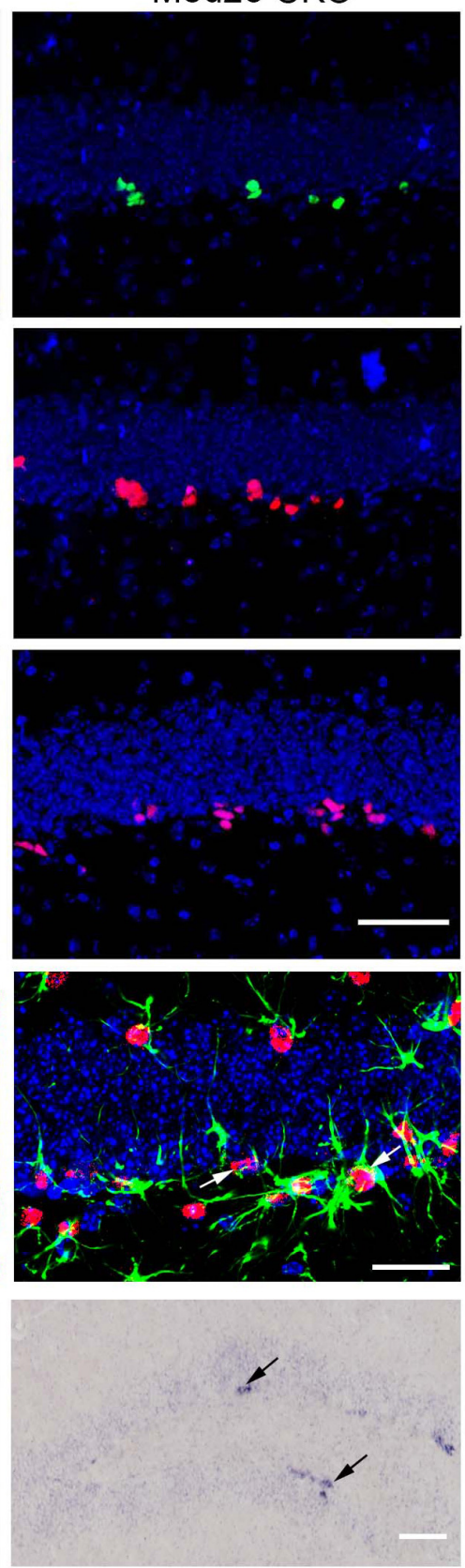
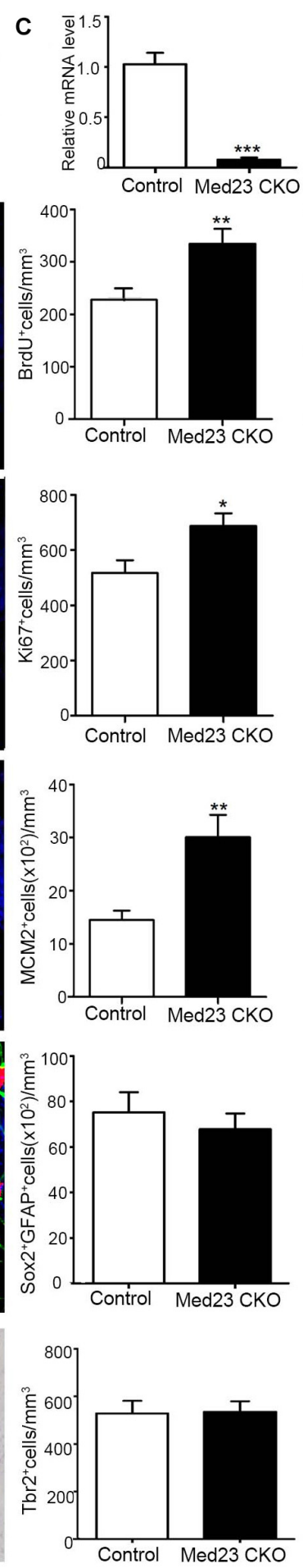

FIGURE 1 | Increased proliferation of Med23-deficient hippocampal NSCs in vivo. (A) Schematic representation of BrdU injection. (B) Western blot of hippocampal tissues of Med23 CKO mice relative to wild type littermates. $N=3$ for each. (C) qPCR data showing the Med23 mRNA levels in the primary neurospheres of control and Med23 CKO. Neurospheres from six control and three Med23CKO mice was included. (D) Distribution and quantification of BrdU+ cells in the SGZ of control and Med23 CKO. Seven control mice and six Med23 CKO mice were included. (E) Distribution and quantification of Ki67 ${ }^{+}$cells in the SGZ of control and Med23 CKO mice. $N=8$ mice in control and seven mice in Med23 CKO groups. (F) Distribution and quantification of $\mathrm{MCM}^{+}$cells in the SGZ of control and Med23 CKO mice. $N=5$ mice in each group. Scale bar $=50 \mu \mathrm{m}$ (D-F). (G) Distribution and quantification of Sox2 ${ }^{+} / \mathrm{GFAP}^{+}$cells (arrows) in the SGZ of control and Med23 CKO. $N=5$ mice in control and six mice Med23 CKO groups. Scale bar $=25 \mu \mathrm{m}$. (H) Distribution and quantification of Tbr2 ${ }^{+}$cells (arrows) in the SGZ of control and Med23 CKO mice. $N=4$ mice in each group. Scale bar $=100 \mu \mathrm{m}$. Data are plotted as the mean \pm SEM. Student $t$-test, ${ }^{\star} p<0.05,{ }^{* \star} p<0.01,{ }^{* \star *} p<0.001$. 
(Figure 1G). The proliferating cells in the SGZ also include progenitors that express Tbr2 (Kalamakis et al., 2019; Morales and Mira, 2019) and there was no obvious alteration in the number of $\mathrm{Tbr}^{+}$cells in the SGZ (Figure 1H). Taken together, although the whole population of NSCs is not changed the active NSCs is likely to be increased in the SGZ of adult Med23 CKO mice.

To further confirm this observation, we isolated hippocampal NSCs from Med23 CKO and control mice and cultured them for 8 days until primary neurospheres were formed. The size of primary neurospheres was significantly increased in cultures from Med23 CKO mice relative to controls (Figure 2A). Next, the primary neurospheres were dissociated into single cells and cultured to form secondary neurosphere. The size of secondary neurospheres was also larger in Med23-deficient NSCs than in control NSCs (Figure 2B). Primary neurospheres were treated with BrdU for $4 \mathrm{~h}$ and the proliferation of cultured NSCs was monitored by BrdU-labeling. The percentage of $\mathrm{BrdU}^{+}$cells in the total cell population was significantly increased in Med23-deficient NSCs compared with control cells (Figure 2C). Taken together, these results suggest that the self-renewal of hippocampal NSCs is enhanced in the absence of Med23.

\section{Reduced Cell Cycle Length of NSCs in Med23 CKO Mice}

There are several possibilities that may underlie the phenotype of increased NSC proliferation, such as enhanced cell cycle entry via recruitment of previously quiescent stem cells, reduced cell cycle exit, or modification of cell cycle length (Fischer et al., 2014). To investigate the increased NSC proliferation in more detail, we first performed double immunostaining of BrdU and Ki67 to estimate cell cycle length. Following BrdU injection (Figure 3A), we calculated the labeling index by the ratio of $\mathrm{BrdU}^{+} / \mathrm{Ki}^{+} 7^{+}$cells in the total of $\mathrm{Ki}^{+} 7^{+}$cells as described previously (Chenn and Walsh, 2002; Qu et al., 2013). This labeling index provides an estimation of cell cycle length, in that a higher index represents a shorter cell cycle and vice versa. The index was 47.7 and $39.5 \%$ in $\mathrm{Med} 23 \mathrm{CKO}$ and control
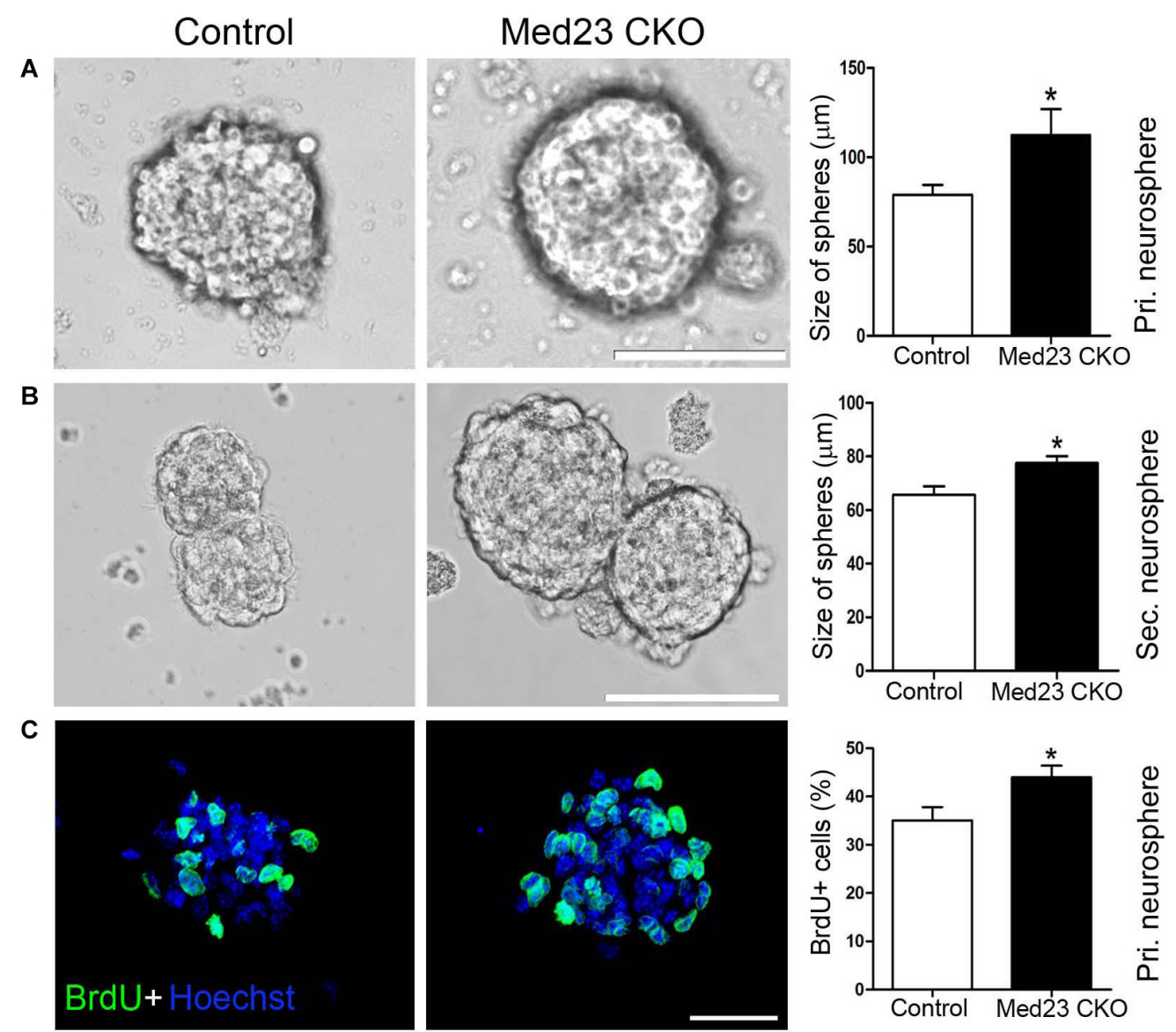

FIGURE 2 | Increased proliferation of Med23-deficient NSCs in vitro. (A,B) Primary and secondary neurospheres cultured from NSCs of control and Med23 CKO mice. About 11 primary neurospheres were obtained from each mice, and a total of eight mice were used in each group. For the analysis of secondary neurospheres, eight neurospheres were included from each mouse and eight mice were used in each group. Scale bars = $100 \mu \mathrm{m}$. (C) Immunostaining of BrdU in primary neurospheres from control and Med23 CKO mice, and comparison of percentages of BrdU ${ }^{+}$cells in the total cell population. About six neurospheres were included from each mouse, and five mice were used in each group. Scale bar $=25 \mu \mathrm{m}$. Data are plotted as the mean \pm SEM. Student $t$-test, ${ }^{*} p<0.05$. 


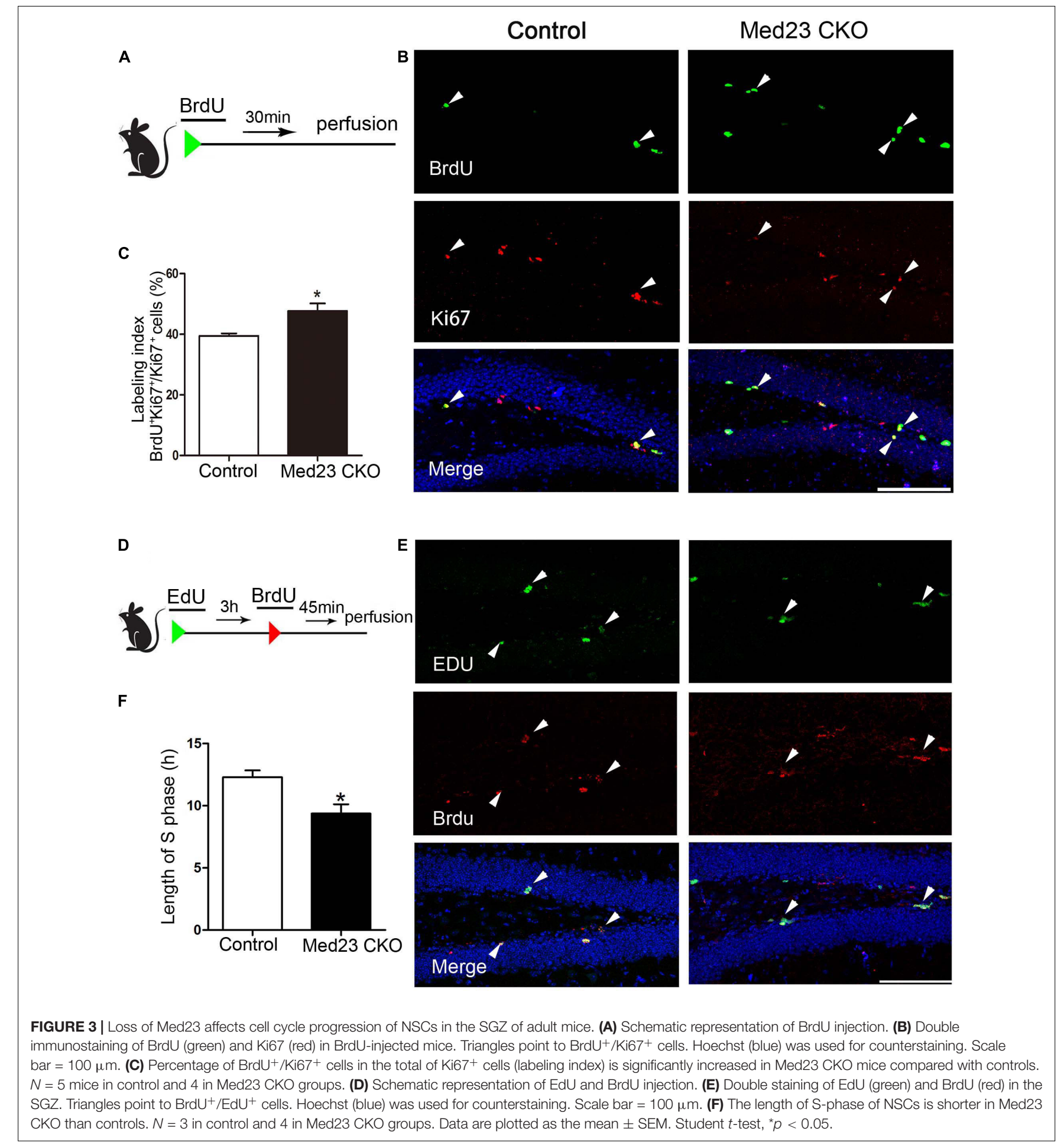

mice, respectively, showing that cell cycle length of hippocampal NSCs is shortened in the absence of Med23 (Figures 3B,C). As the shortened cell cycle length of NSCs may be due to changes of S-phase in relation to the total cell cycle length, we next injected EdU and BrdU in a 3-h interval (Figure 3D) to estimate $\mathrm{S}$-phase by calculation of $3(\mathrm{~h}) \times \mathrm{EdU}^{+} / \mathrm{EdU}^{+} \mathrm{BrdU}^{-}$ cells (Brandt et al., 2012). It showed that the length of S phase in hippocampal NSCs was $9.37 \mathrm{~h}$ in Med23 CKO mice, thus being significantly shorter than in controls (12.29 h) (Figures 3E,F). These results suggest that the reduction of cell cycle length may contribute to the increased proliferation of NSCs in the SGZ of Med23 CKO mice. 


\section{Reduction of Neuroblasts, and Immature and Mature Newborn Neurons in the Hippocampus of Med23 CKO Mice}

Given our finding of the increased proliferation of Med23 CKO NSCs both in vivo and in vitro, we were prompted to examine how neurogenesis is changed in Med23 CKO mice by the examination of molecular markers expressed in different stages of hippocampal neurogenesis (Duan et al., 2008; Zhao et al., 2008; Ming and Song, 2011). TAM was administered at the age of 2 months and sacrificed 4 weeks after the first TAM treatment (Figure 4A). NeuroD mainly expressed by neuroblasts and there was a significant reduction in $\mathrm{NeuroD}^{+}$cells in Med23 CKO mice compared with controls (Figure 4B). In addition, DCX expressed by neuroblasts and immature neurons also displayed a reduction in cell number in Med23 CKO mice (Figure 4C). Thus, although the proliferation of hippocampal NSCs is enhanced, differentiating newborn neurons are reduced in the hippocampus of Med23 CKO mice.

To further confirm this, we generated Med23 CKO:Rosa26YFP mice, in which YFP is expressed in Nestin ${ }^{+}$NSCs and their progeny, including differentiating newborn and mature neurons. We found that $\mathrm{YFP}^{+}$cells were significantly decreased in number in the SGZ of Med23 CKO:Rosa26-YFP mice relative to Nestin$\mathrm{Cre}^{\mathrm{ER}}$ :Rosa26-YFP mice (Figure 4D); the Nestin-Cre ${ }^{\mathrm{ER}}$ :Rosa26YFP mice with Med23 $3^{+/}$genotype showed no obvious changes in the number of $\mathrm{BrdU}^{+}, \mathrm{Ki}^{+}{ }^{+}, \mathrm{MCM}^{+}$, or $\mathrm{DCX}^{+}$cells relative to control mice and used as control mice here. However, the percentage of cells expressing $\mathrm{YFP}^{+} / \mathrm{MCM}^{+}$in $\mathrm{YFP}^{+}$cells was increased in $\mathrm{CKO}$ mice relative to controls (Figure 4E), which is consistent with the increase of NSCs as described above. Thus, the decrease in $\mathrm{YFP}^{+}$cell number is likely caused by a reduction in the number of differentiating and/or mature newborn neurons. Indeed, the percentage of $\mathrm{YFP}^{+} / \mathrm{DCX}^{+}$cells in $\mathrm{YFP}^{+}$cells was reduced in Med23 CKO mice compared with controls (Figure 4F). To explore how many of the $\mathrm{YFP}^{+}$cells were differentiated neurons, we performed NeuN immunostaining. It showed that some $\mathrm{YFP}^{+}$cells expressed $\mathrm{NeuN}$ in both control and CKO mice, but it is percentage of $\mathrm{YFP}^{+} / \mathrm{NeuN}^{+}$cells in $\mathrm{YFP}^{+}$cells was significantly reduced in Med23 CKO mice (Figure 4G). Noted that no significant differences in the proportion of $\mathrm{YFP}^{-} / \mathrm{MCM}^{+}$cells in the total of $\mathrm{MCM}^{+}$or $\mathrm{YFP}^{-} / \mathrm{DCX}^{+}$cells in the population of $\mathrm{DCX}^{+}$cells were detected between the two groups. There results demonstrate that the neurogenesis is impaired in the SGZ of Med23 CKO mice.

In addition, BrdU was administered in 2 month-old mice, and BrdU-labeled newborn neurons were examined 3 weeks later (Figure 5A) by double immunostaining of $\mathrm{BrdU}$ with NeuN (Figure 5B). Quantitative analysis revealed that the number of $\mathrm{BrdU}^{+}$cells (Figure $5 \mathrm{C}$ ) and $\mathrm{BrdU}^{+} / \mathrm{NeuN}^{+}$ neurons (Figure 5C) were significantly decreased in the SGZ of Med23 CKO mice compared with controls. Consistent with the reduction of $\mathrm{GFP}^{+} / \mathrm{NeuN}^{+}$neurons mentioned above, mature new-born neurons are reduced in the DG of Med23 CKO mice, which is likely to be a consequence of the reduction of neuroblasts and immature neurons. In support of this, TUNEL staining and cleaved caspse 3 immunostaining did not detect positive signals in the DG of both control and Med23 CKO.

\section{Defective Dendritic Arborization of Newborn Neurons in Med23 CKO Mice}

We next examined dendritic morphogenesis of the surviving newborn neurons in Med23 CKO mice. To this end, we stereotactically injected GFP-expressing retrovirus infecting dividing cells into the DG, and examined dendritic tree of newborn neurons 3 weeks later. Sparse labeling of newborn neurons allowed us to clearly visualize and quantify the dendritic arborization of individual newborn neurons. Dendritic length of GFP-labeled neurons was reduced (Figure 6A) and dendrites were less branched in Med23 CKO mice relative to controls (Figure 6B). These findings are consistent with DCX immunostainings in which we observed many fewer dendrites in $\mathrm{DCX}^{+}$neuroblasts in the SGZ of Med23 CKO mice compared with controls (Figure 4C). Thus, the loss of Med23 leads to aberrant dendritic morphogenesis of newborn neurons in the SGZ.

\section{Defective Spatial Memory and Contextual Fear Memory in Med23 CKO Mice}

The Morris water maze was used to investigate hippocampusdependent spatial learning and memory. Spontaneous locomotor activity was examined in the open field test first, and no differences were observed in traveled distance or velocity between the two groups (data not shown). In the training phase of Morris water maze, the learning curves shown by escape latencies in finding the platform over a 6-day training was comparable, although the latency was significantly increased in Med23 CKO mice as compared with controls on day 4 (Figure 7A). One day after the 6-day training, we examined the retrieval of spatial memory in the absence of the platform. Med23 CKO mice required significantly more time to locate the platform (Figure 7B), spent less time in the platform zone (Figure 7C) and had a reduced frequency of crossing the platform in the probe test compared with control mice (Figure 7D). It should be noted that Med $23 \mathrm{CKO}$ and control mice showed similar velocity during the training and probe test. Thus, a deficiency in spatial memory was observed in Med23 CKO mice.

Adult hippocampal neurogenesis has been shown to be implicated in contextual fear memory (Antunes and Biala, 2012). To explore whether the acquisition and retrieval of the fear memory was changed in Med23 CKO mice, we conducted a contextual fear test as described in our previous studies (Dai et al., 2008; Song et al., 2016). Contextual fear conditioning was tested using foot shocks, and the freezing behavior was measured as the percentage of time spent in freezing during the conditioning and retrieval periods. Interestingly, the freezing behavior was not different during the initial four postshock intervals, but significantly decreased after the final foot shock in Med23 CKO mice relative to controls (Figure 7E), suggesting a mild impairment in the acquisition of contextual fear 


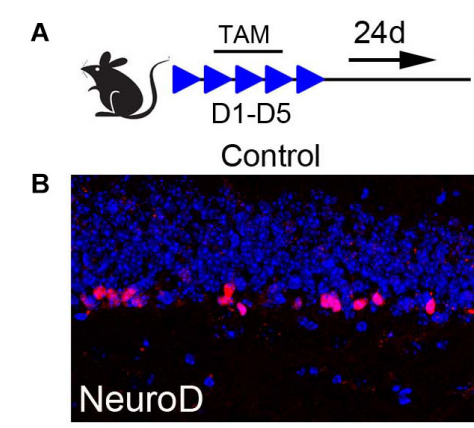

perfusion
D30
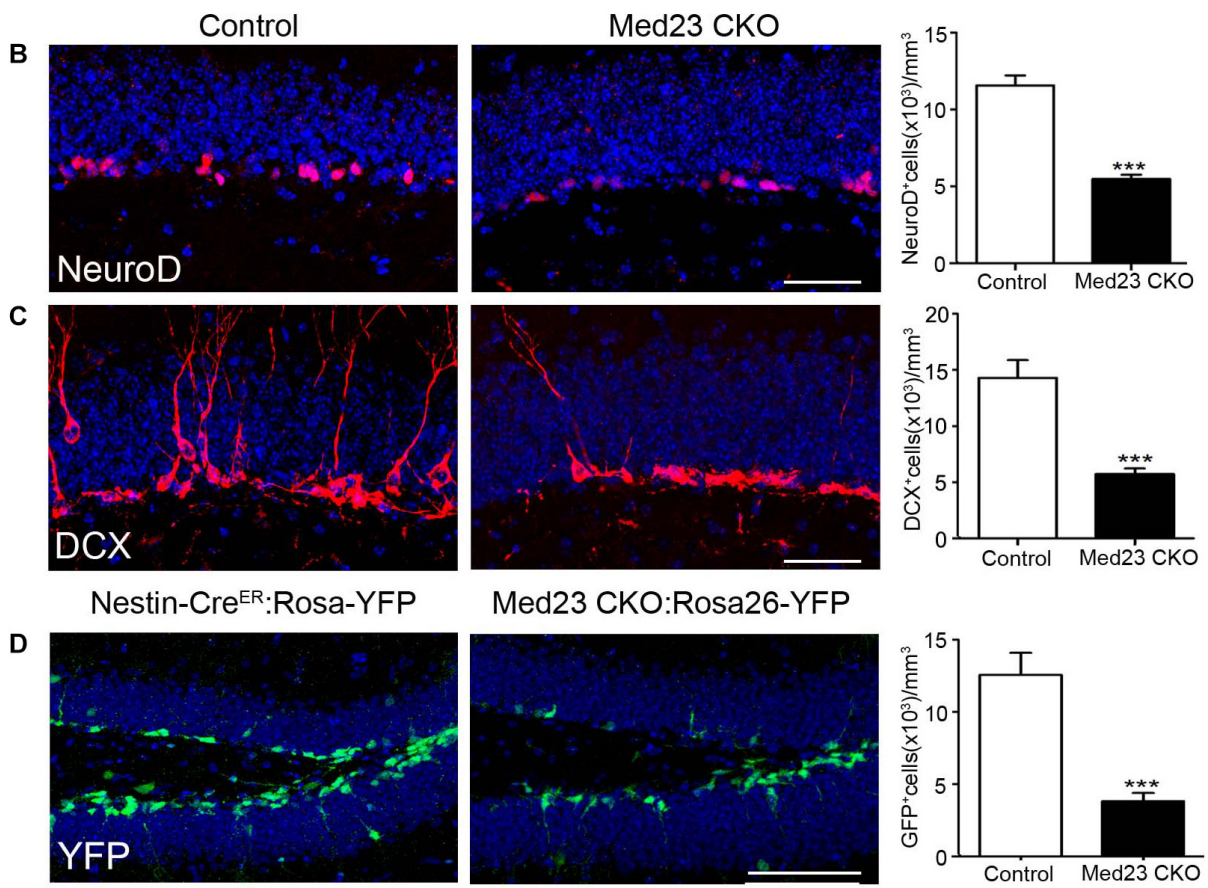

E
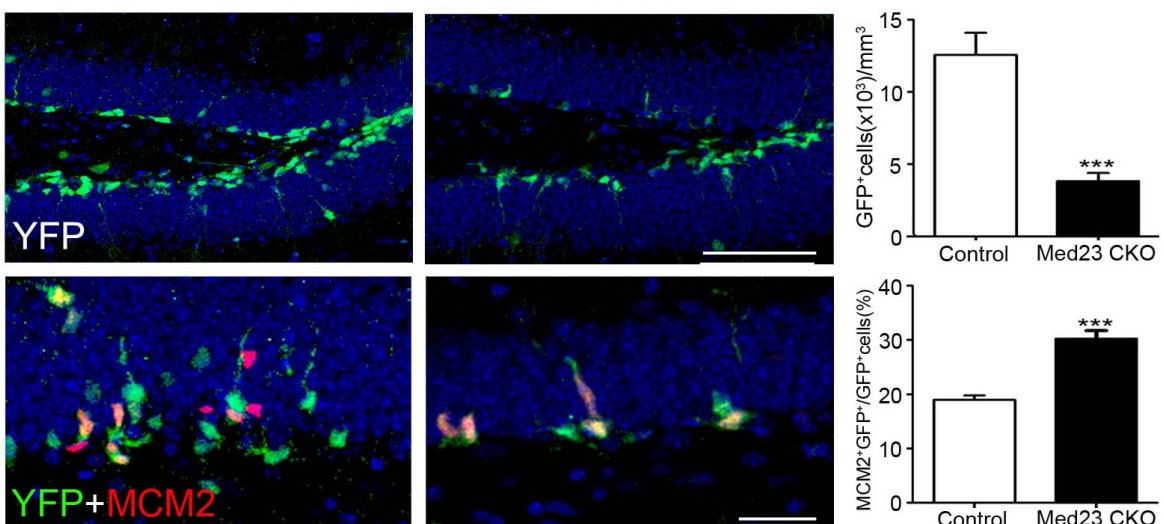

$\mathbf{F}$
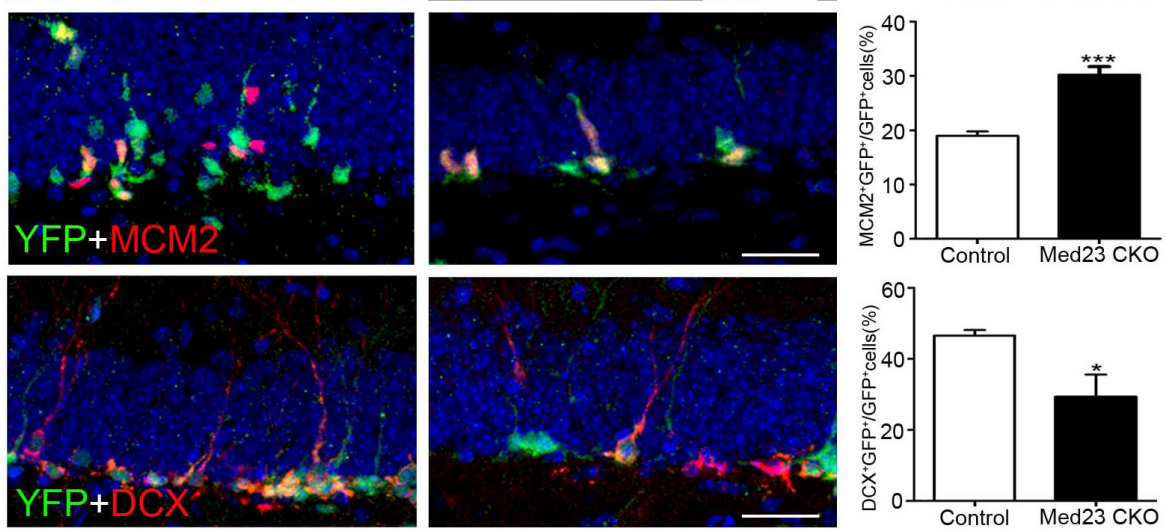

G
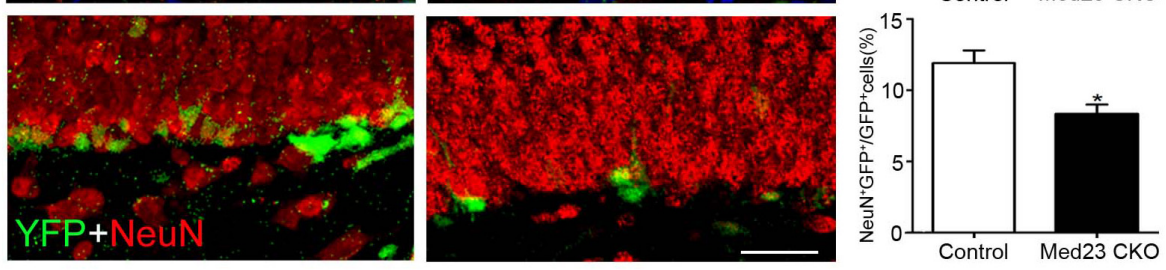

FIGURE 4 | Med23 deficiency results in a reduction of neuroblasts and immature newborn neurons in the SGZ. (A) Schematic representation of TAM treatment. $(\mathbf{B}, \mathbf{C})$ Distribution and quantification of NeuroD ${ }^{+}$and DCX+ cells in the SGZ of Med23 CKO mice compared with controls. $\mathrm{N}=6$ in control and 4 in $\mathrm{Med} 23 \mathrm{CKO}$ groups (B) and $n=5$ in each group (C). (D-G) Distribution and quantification of YFP-expressing cells (green, D), and its combination with MCM2 (red, E), DCX (red, F), and NeuN (red, G) in the SGZ of Med23 CKO:Rosa26-YFP mice and control Nestin-Cre ${ }^{E R}:$ Rosa26-YFP with Med23 ${ }^{+/+}$genotype. $N=5$ mice in each group (D); $n=4$ mice in control and 3 mice in Med23 CKO groups $(\mathbf{E}-\mathbf{G})$. Scale bars $=25 \mu \mathrm{m}$. Data are plotted as the mean \pm SEM. Student $t$-test, ${ }^{\star} p<0.05,{ }^{\star \star \star} p<0.001$.

memory. When placed back into the conditioned surrounding in the absence of foot shocks, Med23 CKO mice showed less freezing behavior at $30 \mathrm{~min}$, day 1 and day 7 (Figure 7F) post freezing conditioning compared with control mice. The learning and retrieval of contextual fear memory is defective in Med23 CKO mice.

As the above results reflect the possibility that spatial memory and contextual fear memory are impaired in the absence of 

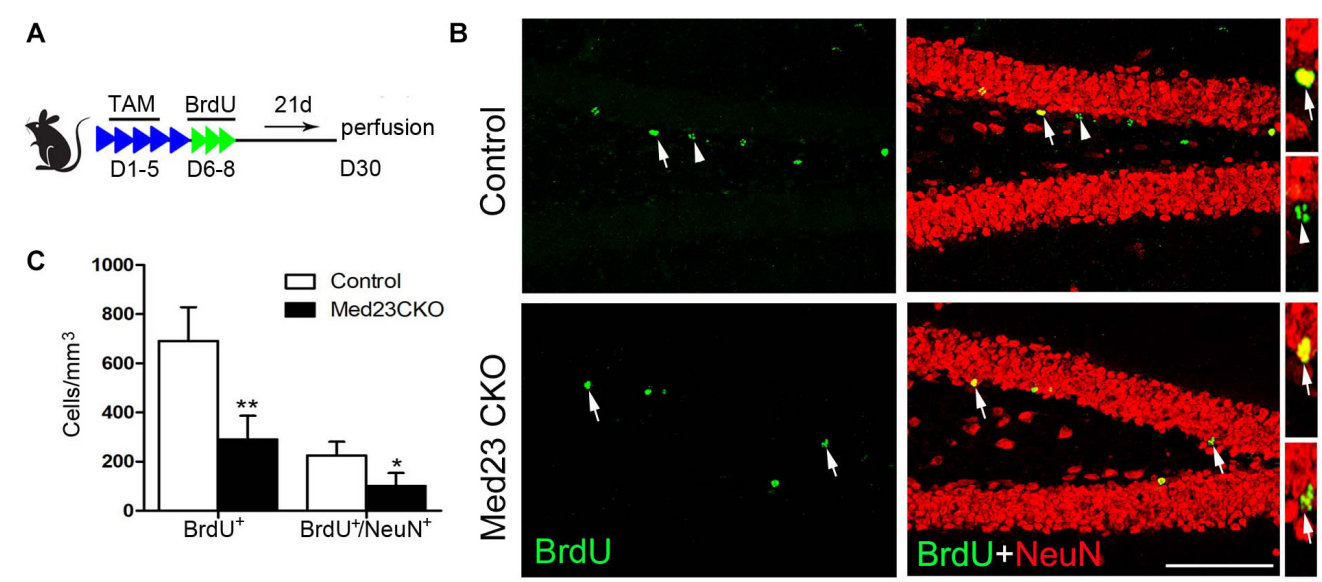

FIGURE 5 | Mature new-born neurons is also reduced in Med23 CKO mice. (A) Schematic representation of TAM treatment and BrdU injection protocol for the examination of newborn neuron survival. (B) Double immunostaining of BrdU (green) and NeuN (red). Arrows point to BrdU/NeuN-double positive cells and triangles point to cells labeled with BrdU only. Scale bar $=100 \mu \mathrm{m}$. (C) Quantification data show that the numbers of BrdU-single and BrdU/NeuN-double positive cells are significantly reduced in Med23 CKO mice compared with controls. $N=5$ in each group. Data are plotted as the mean \pm SEM. Student $t$-test, ${ }^{*} p<0.05,{ }^{* \star} p<0.01$.
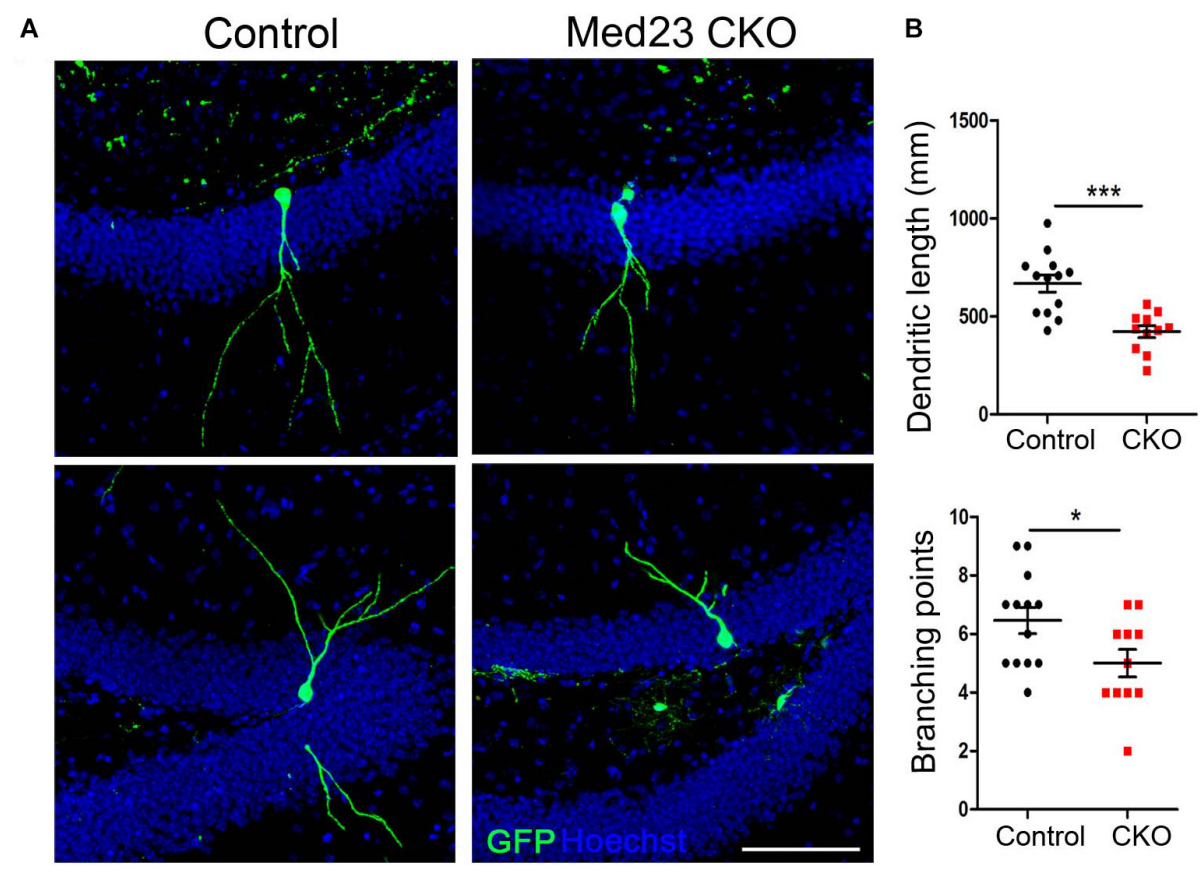

FIGURE 6 | Aberrant dendritic morphogenesis of newborn neurons in Med23 CKO mice. GFP-encoding retrovirus was injected into the dentate gyrus and analyzed 3 weeks later. (A) Representative confocal images showing dendrites of newborn neurons in the SGZ of Med23 CKO and control mice. Hoechst (blue) was used as counterstaining. Scale bar $=100 \mu \mathrm{m}$. (B) Quantification of the total dendritic length and total branching points of GFP ${ }^{+}$newborn neurons. A total of 13 neurons from 3 control and 11 neurons from 3 Med23CKO mice were included. Data are plotted as the mean \pm SEM. Student $t$-test, ${ }^{*} p<0.05$, ${ }^{* \star *} p<0.001$.

Med23, we then performed a novel object recognition test to evaluate object recognition memory between two groups. Firstly, we identified no differences in the location index between Med23 CKO and control mice (Figure 7G). We then measured cognitive function using a preference index as described previously (Wang et al., 2007). Both mice showed a preference to the novel object, and no differences in preference index were observed between Med23 CKO and control mice (Figure $7 \mathbf{H}$ ), suggesting that Med23-deficient may not affect recognitive memory.

\section{Transcript Profiling of Med23-Deficient NSCs}

To explore possible cues for future exploring mechanisms underlying the increased number of NSCs and reduced 

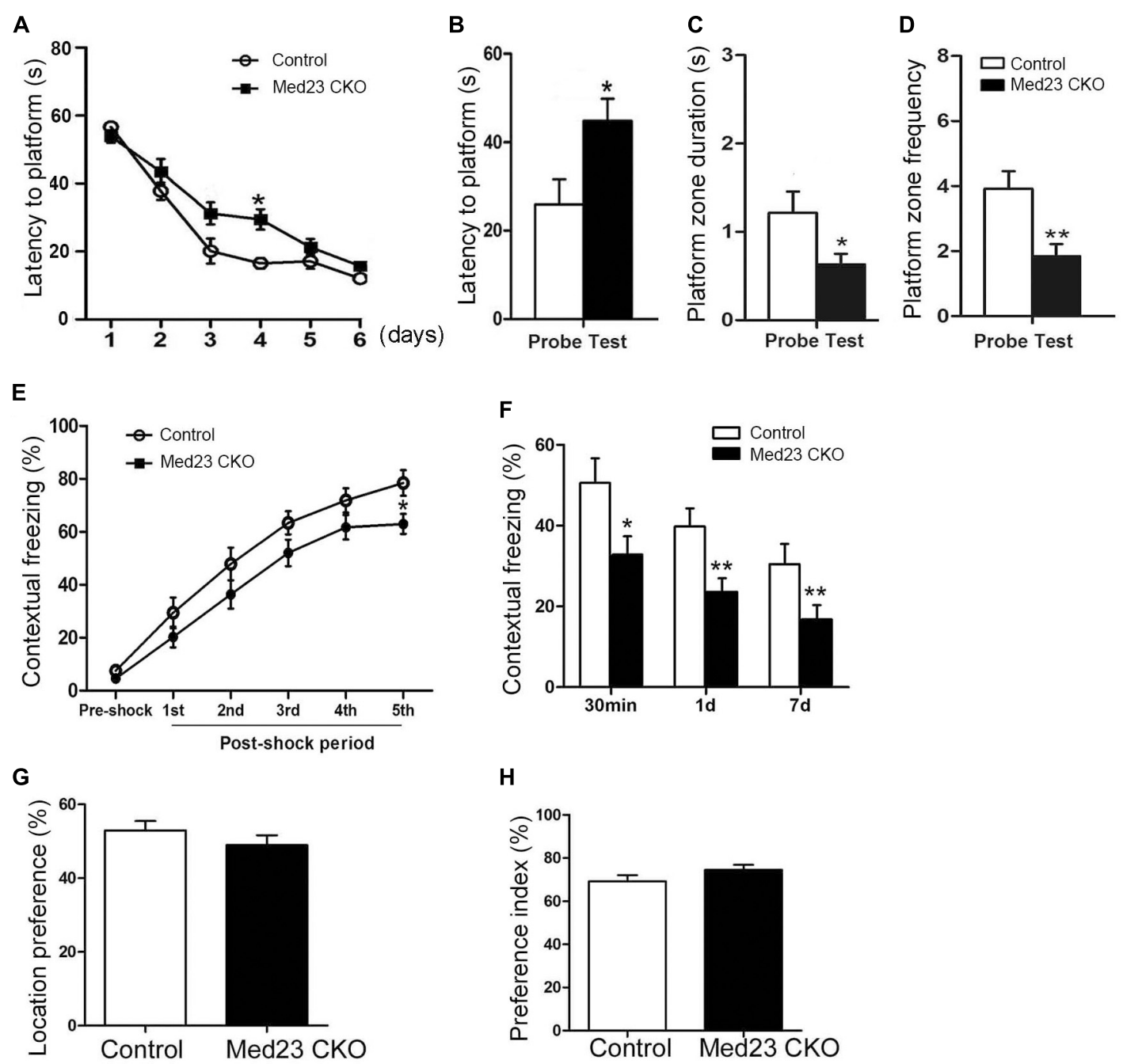

FIGURE 7 | Defective spatial memory and contextual fear memory in Med23 CKO mice. (A-D) Morris water maze test. Learning curve of Med23 CKO mice is similar to that of control mice in the probe training except at day 4 (A), but in the probe test Med23 CKO mice show longer latency to platform (B), less time spent in the platform zone (C), and reduced frequency of crossing the platform (D) compared with controls. (E,F) Contextual fear memory test. Foot shocks provoke a significant decrease in freezing behavior at 5th shock in Med23 CKO mice during conditioning period (E), and Med23 CKO mice also display reduced freezing behavior in the retrieval of contextual fear memory at all time points post conditioning compared with control mice $\mathbf{( F )}$. (G,H) In the novel object recognition test, no differences in location index $\mathbf{( G )}$ and recognition index $\mathbf{( H )}$ are detected between Med23 CKO and control mice. $\mathrm{N}=12$ mice in control and 13 mice in Med23 CKO groups $\mathbf{( A - F ) ; ~}$ $n=7$ mice in control and 8 in Med23 CKO groups $(\mathbf{G}, \mathbf{H})$. Data are plotted as the mean \pm SEM. Student $t$-test, ${ }^{*} p<0.05,{ }^{* \star} p<0.01$.

survival of newborn neurons in the SGZ of Med23-deficient mice, we performed transcriptome profiling and analyzed global gene expression patterns of primary neurospheres from Med23 CKO and control mice (Figure 8A, GSE152113). We detected genes that were upregulated (667 genes) or downregulated (196 genes) in Med23-deficient NSCs relative to controls $(-\log 10 p<0.05$, Figure $8 \mathrm{~B})$. GO analysis revealed that the upregulated genes show an enrichment for cell proliferation (e.g., SAT1, TNF, IGF1, CD37, and EREG), Notch signaling pathway (e.g., DLL4, HEYL, PSEN2, TGFBR2, NOTCH4, and FOXC1) and apoptotic processes (e.g., TSPO, TNF, CYP1B1, PTGS2, MMP9, TLR4, TGFB1, PSEN2, and CASP1) (Figure 8C). Downregulated genes were observed to be enriched for multiple processes important for nervous system development (e.g., SFRP2, SFRP4, SFRP5, EGR1, EGR2, EGR4, DLL1, MYT1, SLITRK1, FOS, FGFR3, SHH, CDKN2A, Wnt7B, and Wnt8B), positive regulation of transcription from Pol II promoter (EGR1, EGR2, RFX4, EGR4, GRIN1, GSX1, BARHL2, NR4A1, BEX2, IGF2, DLL1, HMGA2, MYT1, MEIS1, SHH, FOS, CDKN2A, BARX2, SFRP2, BMPR1B, MYC, AGAP2, andPEG3), and transcription from Pol II (EGR1, FOS, POLR2F, EGR2, MYC, and CHD5) in Med23-deficient NSCs (Figure 8D). Furthermore, analysis of protein-protein interaction networks among upregulated and downregulated genes indicated dysregulations in the regulatory networks involved in cell proliferation, apoptotic processes and neural development in Med23-deficient NSCs (Figures 8E,F). Together, gene regulatory networks particularly in cell proliferation, apoptotic processes 

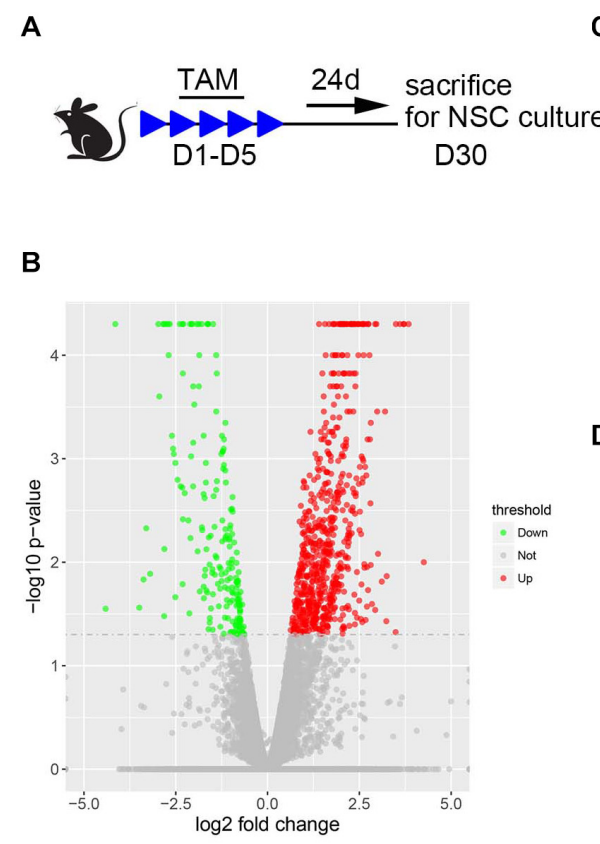

C

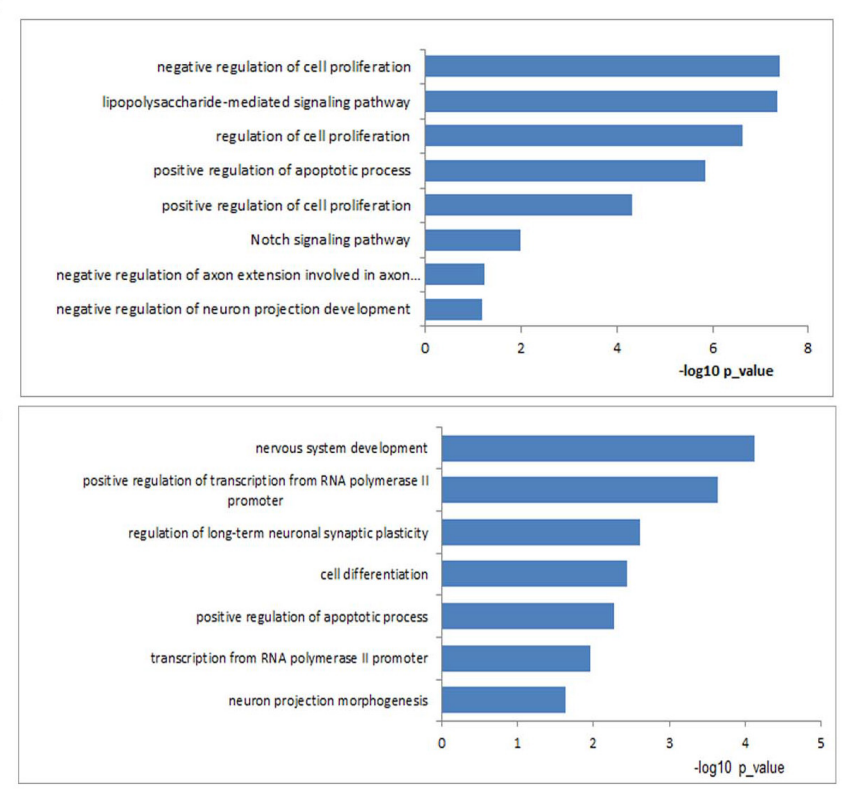

F
E

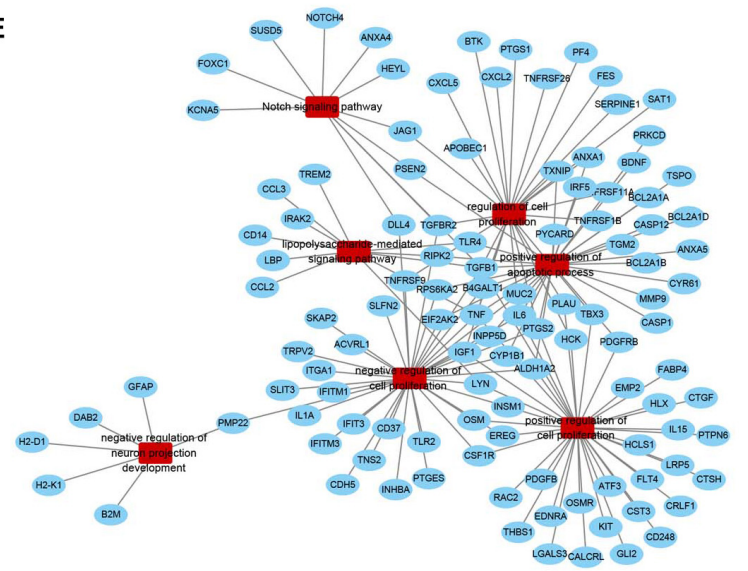

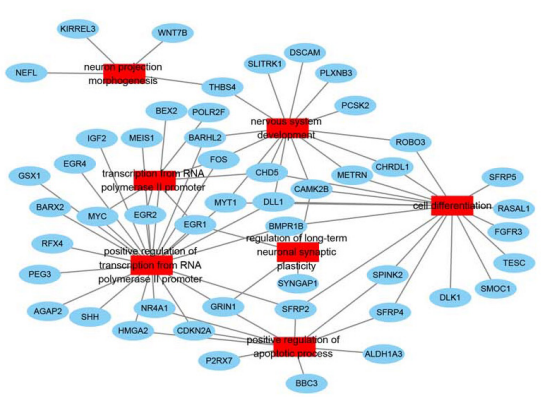

FIGURE 8 | Transcript profiling of Med23-deficient hippocampal NSCs. (A) Schematic representation of TAM treatment and sample collection schedule. (B) Volcano plots depict gene expression changes between Med23 CKO and control NSCs. Significantly differential transcripts are highlighted in color and totaled in each direction (FDR < 0.05). The cultured neurospheres prepared from individual mouse brain were collected as one sample for RNAseq analysis, and $n=3$ in each group. (C,D) Gene ontology (GO) analysis of the significantly upregulated (C) and downregulated (D) genes between Med23 CKO and control NSCs. (E,F) Protein-protein interaction networks among upregulated (E) and downregulated (F) genes in Med23 CKO NSCs.

and neural development are disturbed in the absence of Med23 in adult hippocampal NSCs.

\section{DISCUSSION}

Whilst several physiological functions have been attributed to Med23, its role in the central nervous system has not been examined in vivo. In this study, we focused on adult hippocampal neurogenesis in order to explore the potential role of Med23 in the adult brain as the biological processes are well documented with multiple and reliable study tools. By crossing with Nestin-Cre ${ }^{E R}$ mice, Med23 in hippocampal NSCs could be inactivated by administration of tamoxifen in adult Med23 CKO mice. Conditional inactivation of Med23 in NSCs showed that the loss of this protein leads to an increase of proliferating NSCs but decreases of neuroblasts and new-born neurons in the hippocampus.

The deletion of Med23 with the help of Nestin-Cre ${ }^{\mathrm{ER}}$ causes an increase of $\mathrm{BrdU}^{+}, \mathrm{Ki}^{+} 7^{+}$, and $\mathrm{MCM} 2^{+}$cells with no changes in $\mathrm{GFAP}^{+} / \mathrm{Sox}^{+}$and Tbr2 $2^{+}$populations, suggesting that active NSCs is selectively affected in the population of proliferating cells in the SGZ. However, the populations of neuroblasts and immature new-born neurons shown by $\mathrm{DCX}^{+}$and NeuroD ${ }^{+}$ cells in Med23 CKO mice and $\mathrm{YFP}^{+}$cells in Med23 CKO:Rosa26YFP mice are significantly reduced. According to the data 
from single-cell transcriptomics (Llorens-Bobadilla et al., 2015), Med23 is expressed in all cell types with higher levels in active NSCs and neuroblasts in the hippocampal neurogenic niche. Thus, active NSCs and immature new-born neurons require Med23 to maintain its normal biological functions in the SGZ.

In the exploration of possible cellular events leading to the increase of active NSCs, we found that the cell cycle length of proliferating cells in the SGZ is shortened as a result of reduced S-phase length. However, this does not rule out additional possibilities, such as increased cell cycle entry of quiescent NSCs or decreased cell cycle exit of proliferating NSCs toward a quiescent state or differentiation. The methods employed here is originally used in studying the cell cycle of NSCs in the ventricular zone of developing cerebral cortex where homogenous NSCs are located (Chenn and Walsh, 2002), and it was used in addressing the same question in the SGZ later (Qu et al., 2013). However, the progenitors are intermingled with NSCs in the SGZ, and they may have a different cell cycle length, which therefore contributes to the cell cycle phenotypes observed in the SGZ of Med23-CKO mice. This should be clarified in further study.

One of our previous studies has shown that Med23deficient murine embryonic stem cells show enhanced neural differentiation through modulating BMP signaling (Zhu et al., 2015). In the present study, we show that Med23 is also required for the proliferation of adult hippocampal NSCs and the differentiation of neuroblasts and immature newborn neurons. To our knowledge, this is the first report exploring the role of Med family in the nervous system. As mentioned above, the mammalian Mediator complex is essential to the basal transcription machinery by forming a link between transcription factors and Pol II, whereby it helps regulating the transcription of a large number of proteincoding genes. Consistently, our RNA-seq data show that 667 genes are up- and 196 genes are downregulated in Med23deficient NSCs. The downregulated portion shows an enrichment for genes involved in Pol II-mediated transcription, multiple processes involved in nervous system development and cell differentiation. In the down-regulated genes of Med23-deficient NSCs, the expression of early response genes (such as Egr1, Egr2, Egr4) that are normally induced by serum growth factor (such as SFRP) activation, are greatly attenuated. These results are consistent with our previous study that Egr1 is the most severely affected by loss of MED23 (Wang et al., 2005). However, Med23-deficient embryonic stem cells display enhanced neural differentiation via BMP signaling (Sun et al., 2014), which is not significantly altered in Med23-deficient hippocampal NSCs.

As mentioned above, Med23 is highly expressed in active NSCs and neuroblasts and the cellular phenotypes are present in the two type of cells suggesting possible cell-autonomous role of Med23 in regulating adult hippocampal neurogenesis. According to the transcript profiling data, Notch pathway is upregulated in the absence of Med23. Notch pathway is required for the maintenance of proliferation capability of NSCs and prevent neuronal differentiation (Louvi and ArtavanisTsakonas, 2006), and the upregulation of Notch signaling pathway may contribute to the enhanced proliferation of hippocampal NSCs in the absence of Med23. However, Nestindriven Cre expression is also present in the endothelial cells, and Dll4 and Notch4 are mostly expressed by the endothelial cells (Swift and Weinstein, 2009). This raises a question of if Notch signaling functions in Med23-involved adult neurogenesis in a non-cell-autonomous way. In addition, the upregulated genes involved in cell proliferation (e.g., SAT1, TNF, IGF1, CD37, and EREG) may be implicated in the phenotypes of abnormal neurogenesis of Med23 CKO mice as well. Further studies are needed to explore key downstream effectors that are involved in the Med23-associated transcriptional machinery and regulates adult hippocampal neurogenesis in the mouse brain.

The present findings further demonstrate that Med23 is a factor involved in the regulation of adult hippocampal neurogenesis and its associated role in mouse behavior. As mentioned above, missense mutations in Med23 have been reported in families with autosomal recessive intellectual disability. The mutation (R617Q) leads to a defective response of JUN and FOS immediate early genes to serum mitogens by altering the interaction between enhancer-bound transcription factors (TCF4 and ELK1) and Med23 (Hashimoto et al., 2011; Trehan et al., 2015). Considering the important roles of immediate early genes in brain development, plasticity, and memory formation (Herdegen and Leah, 1998; Tischmeyer and Grimm, 1999; Sanyal et al., 2002; Alberini and Kandel, 2014; Minatohara et al., 2016), it would be interesting to examine possible roles of Med23 in embryonic brain development and in other aspects of adult brain functions. Med23 CKO mice display an impaired performance in the spatial memory, which is consistent with the known functions of adult hippocampal neurogenesis (Ming and Song, 2011; Zhang et al., 2013, 2014), and may be one of factors contributing to the intellectual disability associated with the missense mutation of Med23 (Hashimoto et al., 2011; Trehan et al., 2015). It is well known that animals will learn to link the context itself (the training box) with the foot shocks in contextual fear conditioning, and there is nowadays a consensus that the hippocampus is one of key brain regions for this function (Izquierdo et al., 2016). The Med23 CKO mice show decreased freezing behavior after the last foot shock and during the retrieval period, suggesting impaired fear learning and memory, to which the impaired hippocampal neurogenesis may contribute. In addition, the performance in the object recognition test is normal in Med23 CKO mice. The object recognition can be a different type of memory, which may requires multiple brain regions rather than just the hippocampus.

\section{CONCLUSION}

In summary, we demonstrate that Med23 plays an important role in multiple steps of adult hippocampal neurogenesis including NSC self-renewal and cell cycle progression, as well as spatial and fear memory. These data provide a strong basis for future investigations about possible roles of Med23 in central nervous system development and function. 


\section{DATA AVAILABILITY STATEMENT}

The raw data presented in this study can be found in the GEO, accession number GSE152113.

\section{ETHICS STATEMENT}

The animal study was reviewed and approved by the Animal Care and Use Committees of Tongji University School of Medicine, China.

\section{AUTHOR CONTRIBUTIONS}

G-YC carried out experiments and analyzed the data. SZ, $\mathrm{C}-\mathrm{HL}$, and GW helped with RNA-sequencing experiments. Y-ZW helped with TUNEL staining and WB. C-CQ carried out in situ hybridization. J-YC helped with mouse work. GW, C-JS, and

\section{REFERENCES}

Alberini, C. M., and Kandel, E. R. (2014). The regulation of transcription in memory consolidation. Cold Spring Harb. Perspect. Biol. 7:a021741. doi: 10. 1101/cshperspect.a021741

Antunes, M., and Biala, G. (2012). The novel object recognition memory: neurobiology, test procedure, and its modifications. Cogn. Process. 13, 93-110. doi: 10.1007/s10339-011-0430-z

Botton, P. H., Costa, M. S., Ardais, A. P., Mioranzza, S., Souza, D. O., Da Rocha, J. B., et al. (2010). Caffeine prevents disruption of memory consolidation in the inhibitory avoidance and novel object recognition tasks by scopolamine in adult mice. Behav. Brain Res. 214, 254-259. doi: 10.1016/j.bbr.2010.05.034

Bourbon, H. M., Aguilera, A., Ansari, A. Z., Asturias, F. J., Berk, A. J., Bjorklund, S., et al. (2004). A unified nomenclature for protein subunits of mediator complexes linking transcriptional regulators to RNA polymerase II. Mol. Cell. 14, 553-557.

Brandt, M. D., Hubner, M., and Storch, A. (2012). Brief report: adult hippocampal precursor cells shorten S-phase and total cell cycle length during neuronal differentiation. Stem Cells 30, 2843-2847. doi: 10.1002/stem.1244

Brewer, G. J., and Torricelli, J. R. (2007). Isolation and culture of adult neurons and neurospheres. Nat. Protoc. 2, 1490-1498. doi: 10.1038/nprot.2007.207

Chenn, A., and Walsh, C. A. (2002). Regulation of cerebral cortical size by control of cell cycle exit in neural precursors. Science 297, 365-369. doi: 10.1126/ science. 1074192

Choi, S. H., Bylykbashi, E., Chatila, Z. K., Lee, S. W., Pulli, B., Clemenson, G. D., et al. (2018). Combined adult neurogenesis and BDNF mimic exercise effects on cognition in an Alzheimer's mouse model. Science 361:eaan8821. doi: 10.1126/ science.aan 8821

Chu, Y., Gomez Rosso, L., Huang, P., Wang, Z., Xu, Y., Yao, X., et al. (2014). Liver Med23 ablation improves glucose and lipid metabolism through modulating FOXO1 activity. Cell. Res. 24, 1250-1265. doi: 10.1038/cr.2014.120

Dai, J. X., Han, H. L., Tian, M., Cao, J., Xiu, J. B., Song, N. N., et al. (2008). Enhanced contextual fear memory in central serotonin-deficient mice. Proc. Natl. Acad. Sci. U.S.A. 105, 11981-11986. doi: 10.1073/pnas.0801329105

Ding, Y.-Q., Yin, J., Xu, H.-M., Jacquin, M. F., and Chen, Z.-F. (2003). Formation of whisker-related principal sensory nucleus-based lemniscal pathway requires a paired homeodomain transcription factor, Drg11. J. Neurosci. 23, 7246-7254. doi: 10.1523/jneurosci.23-19-07246.2003

Duan, X., Kang, E., Liu, C. Y., Ming, G. L., and Song, H. (2008). Development of neural stem cell in the adult brain. Curr. Opin. Neurobiol. 18, 108-115.

Fischer, T. J., Walker, T. L., Overall, R. W., Brandt, M. D., and Kempermann, G. (2014). Acute effects of wheel running on adult hippocampal precursor cells in mice are not caused by changes in cell cycle length or S phase length. Front. Neurosci. 8:314. doi: 10.3389/fnins.2014.00314
Y-QD conceived and planned the project. G-YC and Y-QD wrote the manuscript. All authors contributed to the article and approved the submitted version.

\section{FUNDING}

This project is supported by the Shanghai Municipal Science and Technology Major Project (Nos. 2018SHZDZX01 and 19490714300) and ZJLab, the National Natural Science Foundation of China $(31671543,81571332,91232724,31371094$, and 81701327), and the National Key R\&D Program of China (2017YFA0104002 and 2017YFA0102700).

\section{ACKNOWLEDGMENTS}

We thank all of the participants for their commitment to this study.

Hashimoto, S., Boissel, S., Zarhrate, M., Rio, M., Munnich, A., Egly, J. M., et al. (2011). MED23 mutation links intellectual disability to dysregulation of immediate early gene expression. Science 333, 1161-1163. doi: 10.1126/science. 1206638

Hentges, K. E. (2011). Mediator complex proteins are required for diverse developmental processes. Semin. Cell. Dev. Biol. 22, 769-775. doi: 10.1016/j. semcdb.2011.07.025

Herdegen, T., and Leah, J. D. (1998). Inducible and constitutive transcription factors in the mammalian nervous system: control of gene expression by Jun, Fos and Krox, and CREB/ATF proteins. Brain Res. Brain Res. Rev. 28, 370-490. doi: 10.1016/s0165-0173(98)00018-6

Hu, L., Lan, W., Guo, H., Chai, G. D., Huang, K., Zhang, L., et al. (2014). A mouse line for inducible and reversible silencing of specific neurons. Mol. Brain 7:68.

Imayoshi, I., Sakamoto, M., Ohtsuka, T., Takao, K., Miyakawa, T., Yamaguchi, M., et al. (2008). Roles of continuous neurogenesis in the structural and functional integrity of the adult forebrain. Nat. Neurosci. 11, 1153-1161. doi: 10.1038/nn. 2185

Izquierdo, I., Furini, C. R., and Myskiw, J. C. (2016). Fear memory. Physiol. Rev. 96, 695-750.

Kalamakis, G., Brüne, D., Ravichandran, S., Bolz, J., Fan, W., Ziebell, F., et al. (2019). Quiescence modulates stem cell maintenance and regenerative capacity in the aging brain. Cell 176, 1407.e14-1419.e14.

Lewis, B. A., and Reinberg, D. (2003). The mediator coactivator complex: functional and physical roles in transcriptional regulation. J. Cell. Sci. 116, 3667-3675. doi: 10.1242/jcs.00734

Lieberwirth, C., Pan, Y., Liu, Y., Zhang, Z., and Wang, Z. (2016). Hippocampal adult neurogenesis: its regulation and potential role in spatial learning and memory. Brain Res. 1644, 127-140. doi: 10.1016/j.brainres.2016.05.015

Liu, Z., Yao, X., Yan, G., Xu, Y., Yan, J., Zou, W., et al. (2016). Mediator MED23 cooperates with RUNX2 to drive osteoblast differentiation and bone development. Nat. Commun. 7:11149.

Llorens-Bobadilla, E., Zhao, S., Baser, A., Saiz-Castro, G., Zwadlo, K., and MartinVillalba, A. (2015). Single-cell transcriptomics reveals a population of dormant neural stem cells that become activated upon brain injury. Cell Stem Cell 17, 329-340. doi: 10.1016/j.stem.2015.07.002

Louvi, A., and Artavanis-Tsakonas, S. (2006). Notch signalling in vertebrate neural development. Nat. Rev. Neurosci. 7, 93-102. doi: 10.1038/nrn1847

Malik, S., and Roeder, R. G. (2005). Dynamic regulation of pol II transcription by the mammalian Mediator complex. Trends Biochem. Sci. 30, 256-263. doi: 10.1016/j.tibs.2005.03.009

Malik, S., and Roeder, R. G. (2010). The metazoan Mediator co-activator complex as an integrative hub for transcriptional regulation. Nat. Rev. Genet. 11, 761772. doi: $10.1038 / \mathrm{nrg} 2901$ 
Minatohara, K., Akiyoshi, M., and Okuno, H. (2016). Role of immediate-early genes in synaptic plasticity and neuronal ensembles underlying the memory trace. Front. Mol. Neurosci. 8:78. doi: 10.3389/fnmol.2015.00078

Ming, G. L., and Song, H. (2011). Adult neurogenesis in the mammalian brain: significant answers and significant questions. Neuron 70, 687-702. doi: 10 . 1016/j.neuron.2011.05.001

Morales, A. V., and Mira, H. (2019). Adult neural stem cells: born to last. Front. Cell. Dev. Biol. 7:96. doi: 10.3389/fcell.2019.00096

Pruski, M., Hu, L., Yang, C., Wang, Y., Zhang, J. B., Zhang, L., et al. (2019). Roles for IFT172 and primary cilia in cell migration, cell division, and neocortex development. Front. Cell. Dev. Biol. 7:287. doi: 10.3389/fcell.2019.00287

Qu, Q., Sun, G., Murai, K., Ye, P., Li, W., Asuelime, G., et al. (2013). Wnt7a regulates multiple steps of neurogenesis. Mol. Cell. Biol. 33, 2551-2559. doi: $10.1128 / \mathrm{mcb} .00325-13$

Romer, B., Krebs, J., Overall, R. W., Fabel, K., Babu, H., Overstreet-Wadiche, L., et al. (2011). Adult hippocampal neurogenesis and plasticity in the infrapyramidal bundle of the mossy fiber projection: I. Co-regulation by activity. Front. Neurosci. 5:107. doi: 10.3389/fnins.2011.00107

Salic, A., and Mitchison, T. J. (2008). A chemical method for fast and sensitive detection of DNA synthesis in vivo. Proc. Natl. Acad. Sci. U.S.A. 105, 2415-2420. doi: 10.1073/pnas.0712168105

Santarelli, L., Saxe, M., Gross, C., Surget, A., Battaglia, F., Dulawa, S., et al. (2003). Requirement of hippocampal neurogenesis for the behavioral effects of antidepressants. Science 301, 805-809. doi: 10.1126/science.1083328

Sanyal, S., Sandstrom, D. J., Hoeffer, C. A., and Ramaswami, M. (2002). AP-1 functions upstream of CREB to control synaptic plasticity in Drosophila. Nature 416, 870-874. doi: 10.1038/416870a

Singh, N., and Han, M. (1995). sur-2, a novel gene, functions late in the let-60 ras-mediated signaling pathway during Caenorhabditis elegans vulval induction. Genes Dev. 9, 2251-2265. doi: 10.1101/gad.9.18.2251

Song, N. N., Jia, Y. F., Zhang, L., Zhang, Q., Huang, Y., Liu, X. Z., et al. (2016). Reducing central serotonin in adulthood promotes hippocampal neurogenesis. Sci. Rep. 6:20338.

Stevens, J. L., Cantin, G. T., Wang, G., Shevchenko, A., Shevchenko, A., and Berk, A. J. (2002). Transcription control by E1A and MAP kinase pathway via Sur2 mediator subunit. Science 296, 755-758. doi: 10.1126/science.1068943

Sun, Y., Zhu, X., Chen, X., Liu, H., Xu, Y., Chu, Y., et al. (2014). The mediator subunit Med23 contributes to controlling T-cell activation and prevents autoimmunity. Nat. Commun. 5:5225.

Swift, M. R., and Weinstein, B. M. (2009). Arterial-venous specification during development. Circ. Res. 104, 576-588. doi: 10.1161/circresaha.108.188805

Tischmeyer, W., and Grimm, R. (1999). Activation of immediate early genes and memory formation. Cell. Mol. Life Sci. 55, 564-574. doi: 10.1007/ s000180050315

Trapnell, C., Pachter, L., and Salzberg, S. L. (2009). TopHat: discovering splice junctions with RNA-Seq. Bioinformatics 25, 1105-1111. doi: 10.1093/ bioinformatics/btp 120

Trapnell, C., Roberts, A., Goff, L., Pertea, G., Kim, D., Kelley, D. R., et al. (2012). Differential gene and transcript expression analysis of RNA-seq experiments with TopHat and Cufflinks. Nat. Protoc. 7, 562-578. doi: 10.1038/nprot.2012. 016

Trehan, A., Brady, J. M., Maduro, V., Bone, W. P., Huang, Y., Golas, G. A., et al. (2015). MED23-associated intellectual disability in a non-consanguineous family. Am. J. Med. Genet. A 167, 1374-1380. doi: 10.1002/ajmg.a.37047
Vorhees, C. V., and Williams, M. T. (2006). Morris water maze: procedures for assessing spatial and related forms of learning and memory. Nat. Protoc. 1, 848-858. doi: 10.1038/nprot.2006.116

Wang, D., Noda, Y., Zhou, Y., Mouri, A., Mizoguchi, H., Nitta, A., et al. (2007). The allosteric potentiation of nicotinic acetylcholine receptors by galantamine ameliorates the cognitive dysfunction in beta amyloid25-35 i.c.v.-injected mice: involvement of dopaminergic systems. Neuropsychopharmacology 32, 12611271. doi: 10.1038/sj.npp.1301256

Wang, G., Balamotis, M. A., Stevens, J. L., Yamaguchi, Y., Handa, H., and Berk, A. J. (2005). Mediator requirement for both recruitment and postrecruitment steps in transcription initiation. Mol. Cell. 17, 683-694. doi: 10.1016/j.molcel.2005. 02.010

Wang, W., Huang, L., Huang, Y., Yin, J. W., Berk, A. J., Friedman, J. M., et al. (2009). Mediator MED23 links insulin signaling to the adipogenesis transcription cascade. Dev. Cell. 16, 764-771. doi: 10.1016/j.devcel.2009. 04.006

Yang, J., Zhao, Y., Zhang, L., Fan, H., Qi, C., Zhang, K., et al. (2018). RIPK3/MLKLmediated neuronal necroptosis modulates the M1/M2 polarization of microglia/macrophages in the ischemic cortex. Cereb. Cortex 28, 2622-2635. doi: 10.1093/cercor/bhy089

Yang, X., Zhao, M., Xia, M., Liu, Y., Yan, J., Ji, H., et al. (2012). Selective requirement for Mediator MED23 in Ras-active lung cancer. Proc. Natl. Acad. Sci. U.S.A. 109, E2813-E2822.

Yao, X., Tang, Z., Fu, X., Yin, J., Liang, Y., Li, C., et al. (2015). The Mediator subunit MED23 couples H2B mono-ubiquitination to transcriptional control and cell fate determination. EMBO J. 34, 2885-2902. doi: 10.15252/embj.201591279

Yin, J. W., Liang, Y., Park, J. Y., Chen, D., Yao, X., Xiao, Q., et al. (2012). Mediator MED23 plays opposing roles in directing smooth muscle cell and adipocyte differentiation. Genes Dev. 26, 2192-2205. doi: 10.1101/gad.192666.112

Zhang, J., Ji, F., Liu, Y., Lei, X., Li, H., Ji, G., et al. (2014). Ezh2 regulates adult hippocampal neurogenesis and memory. J. Neurosci. 34, 5184-5199. doi: 10. 1523/jneurosci.4129-13.2014

Zhang, R.-R., Cui, Q.-Y., Murai, K., Lim, Y. C., Smith, Z. D., Jin, S., et al. (2013). Tet1 regulates adult hippocampal neurogenesis and cognition. Cell Stem Cell 13, 237-245. doi: 10.1016/j.stem.2013.05.006

Zhao, C., Deng, W., and Gage, F. H. (2008). Mechanisms and functional implications of adult neurogenesis. Cell 132, 645-660. doi: 10.1016/j.cell.2008. 01.033

Zhu, W., Yao, X., Liang, Y., Liang, D., Song, L., Jing, N., et al. (2015). Mediator Med23 deficiency enhances neural differentiation of murine embryonic stem cells through modulating BMP signaling. Development 142, 465-476. doi: 10.1242/dev.112946

Conflict of Interest: The authors declare that the research was conducted in the absence of any commercial or financial relationships that could be construed as a potential conflict of interest.

Copyright (c) 2020 Chen, Zhang, Li, Qi, Wang, Chen, Wang, Ding and Su. This is an open-access article distributed under the terms of the Creative Commons Attribution License (CC BY). The use, distribution or reproduction in other forums is permitted, provided the original author(s) and the copyright owner(s) are credited and that the original publication in this journal is cited, in accordance with accepted academic practice. No use, distribution or reproduction is permitted which does not comply with these terms. 